\title{
Two Varieties of Skepticism
}

\author{
James Conant
}

This paper distinguishes two varieties of skepticism and the varieties of philosophical response those skepticisms have engendered. The aim of the exercise is to furnish a perspicuous overview of some of the dialectical relations that obtain across some of the range of problems that philosophers have called (and continue to call) "skeptical". I will argue that such an overview affords a number of forms of philosophical insight. ${ }^{1}$

\section{Cartesian and Kantian Varieties of Skepticism - A First Pass at the Distinction}

I will call the two varieties of skepticism in question Cartesian skepticism and Kantian skepticism respectively. ${ }^{2}$ (These labels are admittedly contentious. ${ }^{3}$ Nothing of substance hangs on my employing these rather than

1 The taxonomy is meant to serve as a descriptive tool for distinguishing various sorts of philosophical standpoint. It is constructed in as philosophically neutral a fashion as possible. The distinctions presented below upon which it rests are ones that can be deployed by philosophers of very different persuasions regardless of their collateral philosophical commitments. A philosopher could make use of these distinctions to argue for any of a number of very different conclusions. Some of the more specific philosophical claims that I myself express sympathy for in the latter part of this part (e.g., regarding how these varieties of skepticism are related to one another) do, however, turn on collateral philosophical commitments. The taxonomy presented here affords the terminological resources for a precise statement of these claims. It cannot and is not meant to do more.

2 A reason for referring to the taxonomy offered here as "partial" is because the overview of varieties of skepticism set forth here is in no way intended to be exhaustive. On the contrary, much of the point of this paper lies in showing that philosophical illumination can be afforded by an attention to differences among varieties of skepticism. It should be possible to uncover further ways in which it can prove helpful to introduce further distinctions between varieties of skepticism - distinctions that are elided or overlooked in the admittedly schematic taxonomy furnished here. An additional, more particular reason for referring of the taxonomy offered here as "partial" is because it is in no way intend- 
certain other labels that might serve equally well to mark the distinctions to which I will be seeking to draw attention. What matters are the distinctions themselves. ${ }^{4}$ ) Each of these varieties of skepticism has its origin in a skeptical question - I will call these the Cartesian question and the

ed to accommodate (what I take to be) the variety of skepticism which (for lack of a better label) I will call Pyrrhonian skepticism: one which has its roots in ancient skepticism, which remains a (seemingly) live philosophical option until at least Montaigne, and which continues to remain a significant philosophical point of reference to nineteenth-century thinkers as different from one another as Hegel, Kierkegaard, and Nietzsche - each of whom regard it (though not entirely for the same reasons) as not only a distinct but also (as compared with modern varieties) as a philosophically comparatively superior form of skepticism. To try to take proper account of the similarities and differences between this variety of skepticism and the Cartesian and Kantian varieties respectively would make this (already too long) paper unmanageably long. I will, nonetheless, occasionally remark in a passing footnote on some aspect of the relation between the generic features of this comparatively ancient form of skepticism and those of the relatively modern varieties with which I am focally concerned here. A yet further variety of skepticism that some might think ought to be sharply distinguished from the Pyrrhonian, Cartesian, and Kantian varieties respectively is Agrippan skepticism (see Williams (2001), $61 \mathrm{ff}$.) The question of whether Agrippan skepticism is a genuinely distinct variety - and, if so, how it is best formulated in order to bring out its distinctive generic features - is not one that I can afford to take up here.

3 There is much that any conscientious historian of philosophy will find to object to in my choosing to attach these labels to each of these varieties of skepticism: does not (what I am calling) Cartesian skepticism antedate Descartes?; is not the issue of skepticism a sideshow in Descartes' philosophy and hence of relatively minor importance (compared to other things - say, the new science, or the quarrel with the Church) for an understanding of Descartes's work as a whole?; are not features of (what I am calling) the Kantian problematic to be found equally in Descartes?, is not Kant more Cartesian than I suggest he is?, is not skepticism equally a sideshow in Kant's larger endeavor?, and what about Hume? Such objections are directed at the aptness of these labels; and it would take considerable space to respond to each of them. The point of the present note is simply to remark that it would be a mistake to think that the integrity of this project (of distinguishing the varieties of skepticism I choose to label "Cartesian" and "Kantian") is much threatened by such objections. Such objections speak only to the question whether I wouldn't be better advised to re-label the varieties of skepticism with which I am here concerned. Later on, a brief attempt will be made both to explain why I choose these particular labels and to respond to a few objections of the above sort. For the most part, however, such historical worries will have to go unaddressed here.

4 As we shall see, there are - in addition to historical - also philosophical grounds for suspecting the stability of these distinctions. 
Kantian question respectively; and each of these varieties of skeptical question leads to a skeptical paradox - which I will call the Cartesian paradox and the Kantian paradox respectively. I will call the imaginary philosopher who acquiesces in the Cartesian paradox a Cartesian skeptic, and the (even more) imaginary philosopher who acquiesces in the Kantian paradox a Kantian skeptic. The customary response to each of these paradoxes is to seek a way to entitle oneself to do something other than acquiesce in the paradoxical conclusion, by refuting or dissolving or diagnosing or by-passing the paradox in question. This gives rise to two varieties of philosophical problematic, flowing from such attempts to address each of these two sorts of skeptic, that I will call the Cartesian problematic and the Kantian problematic respectively. It is with these twin problematics that I will be primarily concerned here and which I will be discussing and referring to as "varieties of skepticism". According to this unconventional idiom, the term "skepticism" (and its variants, such as "Cartesian skepticism" or "Kantian skepticism") therefore refers not just to one particular sort of philosophical position (i. e., that held by one or another sort of skeptic) but rather to the wider dialectical space within which philosophers occupying a range of apparently opposed philosophical positions (such as "realism", "idealism", "coherentism", etc.) engage one another, while seeking a stable way to answer the skeptic's question in the affirmative rather than (as the skeptic himself does) in the negative. ${ }^{5}$ So, according to the terminology I am here introducing, a philosopher can be concerned with the Cartesian skeptical problematic without himself being a Cartesian skeptic; and, indeed, Descartes was such a philosopher. And, according to this terminology,

5 Such an inclusive use of the term 'skepticism', while unusual, is not unprecedented. For a similarly inclusive use, especially in connection with Cartesian skepticism, see, for example, Cavell (1979):

I do not ... confine the term ['skepticism'] to philosophers who wind up denying that we can everknow; Iapply it to any view which takes the existence of the world to be a problem of knowledge.A crucial step for me, in calling an argument skeptical, is that it contain a passage running roughly, "So we don't know (on the basis of the senses (or behavior) alone); then (how) do we know?'.It is at this stage that philosophies break into Phenomenalism, Critical Realism, etc... I hope itwill not seem perverse that I lump views in such a way, taking the very raising of the question ofknowledge in a certain form, or spirit, to constitute skepticism, regardless of whether a philosophytakes itself to have answered the question affirmatively or negatively. It is a perspective from whichskepticism and (what Kant calls) dogmatism are made in one another's image, leaving nothing forchoice. (46) 
the same holds for the relation between being concerned with the Kantian skeptical problematic, being a Kantian skeptic, and being Kant.

The following is an excerpt from the classic formulation of the Cartesian problematic:

How often, asleep at night, am I convinced of just such familiar events that I am here in my dressing-gown, sitting by the fire - when in fact I am lying undressed in bed! Yet at the moment my eyes are certainly wide awake when I look at this piece of paper; I shake my head and it is not asleep; as I stretch out and feel my hand I do so deliberately, and I know what I am doing. All this would not happen with such distinctness to someone asleep. Indeed! As if I did not remember other occasions when I have been tricked by exactly similar thoughts while asleep! As I think about this more carefully, I see plainly that there are never any sure signs by means of which being awake can be distinguished from being asleep.... Suppose then that I am dreaming, and that these particulars - that my eyes are open, that I am moving my head and stretching out my hands - are not true. Perhaps, indeed, I do not even have such hands or such a body at all. ${ }^{6}$

I wish to contrast the skeptical problematic which figures in the above passage with the one which figures in the following excerpt from Kant:

The a priori conditions of a possible experience in general are at the same time conditions of the possibility of objects of experience. Now I maintain that the categories ... are nothing but the conditions of thought in a possible experience.... [A]nd without such unity ... no thoroughgoing, universal, and therefore necessary, unity of consciousness would be met with in the manifold of perceptions. These perceptions would not then belong to any experience, consequently would be without an object, merely a blind play of representations, less even than a dream. ${ }^{7}$

The problematic of the first of these passages centers on how to distinguish between dreaming that one is experiencing something and actually experiencing it. The problematic of the second of these passages centers on what it takes to be able to dream that one is experiencing something. That is to say, the second of these two problematics focuses on the conditions of the possibility of something that the first problematic takes for granted. I take the (apparent) difference here to be a consequential one.

The most familiar way of formulating the contrast between these two problematics is as one of knowledge vs. the conditions of knowledge. Thus one is often told something along the following lines: The Carte-

6 The quotation is drawn from the fifth and sixth paragraphs of Descartes's First Meditation (Descartes (1986)).

7 Kant (1998), A111 f. 
sian wants to arrive at knowledge; the Kantian wants to arrive at the ground of the possibility of knowledge. But what does that mean? There are lots of ways of unpacking this contrast. I will briefly indicate a few of the different points upon which the accent can fall in an unpacking of this contrast. I will, however, want to claim that these apparently distinct formulations can be seen, in the end, to come to the same thing. Here are three ways one might go about unpacking this contrast:

1. Actuality vs. possibility. Cartesian skepticism takes the possibility of experience for granted; its question has to do with actuality. Hence the importance of the word 'real' in Cartesian formulations of the skeptical problematic: are things really as they seem? Kantian skepticism brings within the scope of its worry that which the Cartesian skeptic takes for granted: that experience possesses the requisite unity so much as to be able to be about something. Hence the importance of the word 'possible' in Kantian formulations of the skeptical problematic: how is experience (so much as) possible?

2. Being so vs. being so. ${ }^{8}$ Cartesian skepticism calls into question the veridicality of one's experience; Kantian skepticism calls into question the intelligibility of experience. The Cartesian problematic is concerned with the question: How can I know that things are as they seem? Hence the worry in the Cartesian problematic focuses on an inferential step from appearance to reality. The Kantian problematic is concerned with the question: How can things so much as seem to be a certain way? Hence the worry in the Kantian problematic focuses on the conditions of the possibility of the kind of unity presupposed by the Cartesian (i.e., that which the Cartesian seeks to infer from): what sort of unity must characterize a "play of presentations" for it to be more than "a merely blind play", for it to possess the aspect of offering appearances - for it to possess the character of being of an object.

3. Truth vs. objective purport. The Cartesian wants to know which of his thoughts are true, which of his experiences are veridical. The Cartesian skeptic therefore worries about the transition from a sensory experience to a judgement, from a thought to (what Frege calls) its truth-value. Hence the Cartesian problematic inquires into the

8 I owe this way of formulating the contrast to Stanley Cavell. See Cavell (1979), 45. (However, I make a use of this contrast here - to formulate the distinction between Cartesian and Kantian skepticism - that Cavell himself might not approve of.) 
grounds of truth: given that this is what we are inclined to judge, do we know that we judge truthfully in so judging? The Kantian skeptic seems to deprive us of the resources for so much as being able to enjoy an experience (waking or dreaming), for so much as being able to frame a thought (true or false). The Kantian problematic inquires into the grounds of the possibility of being able to enjoy an experience, entertain a thought-content. The Kantian asks: What does it take to have thoughts that are vulnerable to how things are? The Kantian problematic is concerned, in the first instance, not with truth but with what it is to stick your neck out in thinking, with Kant calls the objective validity of judgment (the possibility of something's being a candidate for truth or falsehood) - with what I will henceforth call the objective purport of judgement.

In any area of philosophy in which one finds one of these two varieties of skepticism, one generally also finds the other. This is not to deny that in some areas of philosophy one of these problematics may come to seem more gripping or otherwise deserving of interest than the other. I do want to argue, however, that wherever one of these sorts of skepticism is possible, the other is also possible. (The fact that these same problematics can and often do surface in virtually every so-called "area" of philosophy is itself a ground for wondering whether philosophy is usefully divided into separate "areas" of inquiry as so many nowadays are prone to suppose.) I will briefly indicate a few of the guises in which the Cartesian and Kantian problematics respectively surface across a number of (supposedly distinct) "areas" of philosophy. But before I do so, it is worth noting one of the many respects in which the labels "Cartesian" and "Kantian" may seem tendentious: namely, as labels for some of the specific variants I shall be concerned to distinguish within (what I am here calling) the "Cartesian" and "Kantian" varieties of skepticism respectively. ${ }^{9}$ Descartes himself, for example, never poses most of the

9 I speak here, rather tentatively, of varieties (rather than genera) of skepticism, and of these varieties as subtending variants (rather than species) of Cartesian and Kantian skepticism respectively, in order to leave open questions concerning how these twin philosophical problematics relate to one another - questions such as: to what extent do they constitute distinct kinds of philosophical worry?, to what extent do they overlap?, or must they mutually exclude one another? I want the terminology I initially employ to introduce the philosophical phenomena under examination in a manner sufficiently neutral so as to allow the question "How, if at all, are these - Cartesian and Kantian - skepticisms related to one another?" to admit of a variety of answers, without pre- 
skeptical worries that I will be calling variants of "Cartesian skepticism". (Indeed, it is arguable that he only ever clearly poses one of them namely, skepticism about the external world.) And, though Kant arguably explores more of the possible variants of (what I will be calling) "Kantian skepticism", he seems to be quite oblivious to some of them. Thus, in claiming that the philosophical problems I mention below represent variants of Cartesian and Kantian skepticism respectively, I am not making an historical claim about which problems are (and are not $^{10}$ ) discussed in the writings of Descartes or Kant. Rather I am making a philosophical claim about a congruence to be found in the shape of the problems themselves, regardless of whose writings they appear in.

In order to gain a clearer sense of what constitutes the unity of a single variety of skepticism, it will help first to consider some variants on a single variety. I will accordingly first present five examples of (what I will call) Cartesian skepticism. I will then go on to present five examples of Kantian skepticism.

judging any particular line of answer. However, as will become clear, I myself do favor a particular line - one that this tentative mode of formulation (in terms of "varieties" rather than "kinds") is particularly concerned to leave room for (namely, that the apparent "kinds" in question here are, in the end, to be recognized as only apparently distinct kinds).

10 The aptness of these labels for the purposes of distinguishing the two varieties of skepticism at issue here are not meant to turn on any claim to the effect that an interest in the other problematic (i.e., the one that does not bear his name) is absent from the writings of either Descartes or Kant. So it does not imply a denial that Kant was interested in Cartesian skepticism. As we shall see later on, Kant addresses a variant of Cartesian skepticism (he calls it "problematical idealism") and seeks in "The Refutation of Idealism" to show how the proper treatment of (what he himself calls) "skepticism" contains as one of its corollaries the untenability of all such forms of idealism. Nor does it turn on a denial that there are incipient forms of a Kantian problematic to be found in Descartes's writings. (Though I do think that such a problematic never comes fully into view in his pages as a full-blown, self-standing variety of skepticism). For some discussion of the presence of an incipiently Kantian problematic in Descartes's thought, see Conant (1992). The evil demon hypothesis of The First Meditation (unlike the dreaming hypothesis), if pressed hard enough, does unfold into (what I call) a Kantian skeptical problematic. The most vivid appearance in the Cartesian corpus of such a problematic is to be found in the treatment of the problem of the creation of eternal truths. But such a problematic is pervasively present in the Cartesian corpus (albeit very incipiently) in the treatment of the fundamental Cartesian issue of what it is for an idea to possess objective reality. 


\section{Five Examples of Cartesian Skepticism}

I begin with the classic case: Cartesian skepticism about perception. The important thing to see here is that this case represents just one instance of a far broader genre:

1. Cartesian skepticism about perception. How can I know things are as my senses present them as being? Is there really an external world? I am having an experience of a certain sort (say, that I am here in my dressing-gown, sitting by the fire) but how can I know that things are as my experience presents them as being? I can have experiences that are indistinguishable from this one (in which I appear to be here in my dressing-gown, sitting by the fire), such as when I am dreaming, and yet things are not as they appear. The case under consideration is a best case of knowledge, and yet there still seems to be room for the question: How can I know that I am not, in fact, lying undressed in my bed dreaming that I am here in my dressing-gown, sitting by the fire? For there are no marks or features that allow one conclusively to distinguish waking from dreaming states. This leads to the following conclusion: if I don't know this, then how can I be said to know anything? Why should I ever trust the testimony of my senses? Should I ever endorse the appearances with which my senses present me? The gap the Cartesian skeptic regarding perception seeks to bridge is from his own mind to the outer world. The outer world is hidden behind the veil of perception. The paradox lies in our apparent inability to answer the following question: How can I penetrate the veil of sensory ideas and attain a view of what is really happening outside of my mind?

In the above case, the knowing subject lies on the mind side of a mind/ world divide. The Cartesian skeptic of perception is left with a problem of the following form: what must I add to (mere) perception to turn it into knowledge? The Cartesian epistemologist's analysis of our perceptual situation turns here on a particular way of conceiving wherein the distinction consists between a veridical and a non-veridical perception. Both cases are conceived as sharing something in common - as possessing what John McDowell calls a highest common factor. ${ }^{11}$ Thus the Cartesian epistemologist is drawn to understand the concept of an appa-

11 McDowell (1998). 
rent perception as follows: An apparent perception of $\mathrm{X}$ is the component in a subject's experience which figures in both a veridical and a non-veridical perceptual experience of $\mathrm{X} .{ }^{12}$ This gives rise then to a further question: what is the something extra which a veridical perception has and a non-veridical perception lacks in virtue of which the latter is veridical and the latter merely apparent. This gives rise to the search for the special something which one must add to a merely apparent conception in order to turn it into a veridical perception. Once the problem is conceived in this form it issues in Cartesian skepticism.

The question which animates the skeptic in the above case is the following: how do we bridge the gap from mind to world - from inner to outer? In order to separate the essential from the accidental within this genre of skepticism, it is helpful to consider the following case next:

2. Cartesian skepticism about other minds. The person before me is acting for all the world as if he were in pain, but how can I know that he is pain. Is he pretending? Or is he really in pain? The case of someone convincingly pretending to be in pain can be indistinguishable from the case of someone actually being in pain. Thus I am not able to conclude that I know he is in pain. For there are no marks or features that conclusively distinguish a case of someone's pretending to be in a state from his being in that state. The conclusion here again takes the form: if I don't know this, how can I ever be said to know what someone else if feeling? The Cartesian problematic here is focused on the problem of how to underwrite the testimony of the human body. The gap the Cartesian seeks to bridge here is from the other's outer bodily movements to his inner states. The inner world of the other is hidden behind the veil of the body. This version of the Cartesian skeptic asks: How can I penetrate the screen of the other's body and attain a view of what is really happening inside the other himself?

In this case, the direction of travel across the mind/world divide has been reversed - the task is now to travel from outer to inner, rather than in the opposite direction - but (what I will call) the form of the problematic is the same. The Cartesian skeptic about other minds is left with a problem of the following form: what must I add to (mere) bodily behavior to turn it into an expression of an inner state? The Cartesian epis-

12 For further discussion of this point, see Thomas Lockhart's paper in this volume. 
temologist's analysis of bodily expressions of our mental life turns here on a particular way of conceiving wherein the distinction consists between a genuine and a merely apparent expression of an inner state. Both cases are again conceived as sharing something in common - as possessing a highest common factor. Thus the Cartesian epistemologist of other minds is drawn to understand the case of someone's pretending to be in pain as follows: The outward bodily pain-behavior is a common component which can figure equally in both a case of someone's pretending to be in pain and someone's being in pain. This gives rise then to a further question: what is the something extra which the case of someone's genuinely being in pain has and someone's pretending to be in pain lacks in virtue of which the latter can yield knowledge of another mind and the latter cannot. This gives rise to the search for the special something - the inner state as such - which one must add to the psychologically neutral layer of mere bodily behavior in order to turn the latter into a case of genuine pain behavior. Once the problem is conceived in this form it issues in Cartesian skepticism, only now it is the screen of the body (rather than the veil of perception) which stands in the way of our being able to gain knowledge of what we want. What makes the behavior count as genuine pain behavior is something which blankly obtains on the other side of the screen, beyond the reach of the gaze of the subject who seeks knowledge of the other's mental states. The pain behavior in this case - like the sensory experience of the outer world in the philosophy of perception case - is conceived in terms which render it by its very nature unable to ground a claim to knowledge, for that which it presents us with (mere sensory experience in the one case, mere bodily behavior in the other) is construed in such a way that it, of necessity, falls short of that (the external world in the one case, the other's inner state in the other) which we seek knowledge.

Let us now move to (what is taken to be) a different area of philosophy altogether: the philosophy of language. This is an area of philosophy in which interest in Kantian skepticism is currently far more dominant than interest in Cartesian skepticism. It is worth noticing, however, that one can also identify a problematic here which exhibits a Cartesian form:

3. Cartesian skepticism about language. How can I know that my interpretation of something (a text, an utterance, a sign-post) is correct? How can I be sure that this is what is really meant? I know how this sort of sign (say, a sign-post in the shape, say, of a pointing 
arrow) is usually to be interpreted, but how do I know that my interpretation in this case is the right interpretation? The physical appearance of the sign (text, utterance) could be indistinguishable across two different contexts of use, and yet the sign can have entirely different meanings in those two different contexts. Thus to understand the sign, I must first interpret it, and it is always possible that my interpretation is incorrect - that it applies to the one context, but not the other. Hence I cannot conclude that I know what the sign here means. But if I don't know this, how can I ever be said to know what something means? The gap that the Cartesian seeks to bridge here is between his understanding of the meaning of a sign and what the sign actually means. The actual meaning of the sign is never present to our view, but only our interpretation of it. This version of the Cartesian skeptic asks: How can I penetrate the penumbra of interpretations which stand between me and the sign and attain knowledge of the meaning of the sign?

The foregoing problem has far more currency presently in English Departments and Law Schools and Art History Departments - that is, in forms of academic and intellectual inquiry which must arrive at a determinate understanding of a particular stretch of text or picture - than it currently has in Philosophy Departments, where the practical task of achieving an understanding of something's meaning can be sacrificed to the broader question of whether such understanding is so much as possible. What matters for our present purposes is that it is a form of problem which can arise. The Cartesian skeptic of language is left with a problem of the following form: what must I add to a mere string of signs in order to turn it something which can support knowledge of their meaning The Cartesian epistemologist's analysis of our linguistic situation turns here on a particular way of conceiving wherein the distinction consists between a veridical and a non-veridical understanding of meaning. Both cases are conceived as sharing something in common - a highest common factor - in this case the particular set of signs which can support differing interpretations. Any case of understanding the meaning of a sign is then analyzed as a case of a mere sign plus an interpretation (on the model of a mere sensory experience plus an outer fact which obtains without in the world, or a mere bodily experience plus an inner state which obtains within the subject). Thus the Cartesian linguist is drawn to understand the case of someone's misunderstanding a linguistic performance as follows: The outwardly perceptible physical 
sign is a common component which can figure equally in both a case of someone's misunderstanding the sign and a case of someone's understanding the sign. This gives rise then to the further question: what is the something extra which must be added to the physical sign, considered in itself, so that the conjunction of the sign plus that extra element can yield knowledge of meaning. This gives rise to the search for the special something - the criterion of meaning - which one must add to the semantically neutral layer of mere linguistic noises or marks in order to turn the latter into a case of genuinely meaningful linguistic behavior.

It is also worth noticing that problems of a Cartesian form arise no less in practical philosophy than in theoretical philosophy. Consider the following case:

4. Cartesian skepticism about intentional action. The person before me appears to be raising his hand, but how can I know that he is raising his hand. The movement of his limbs is certainly indistinguishable from what it would be if he were raising his hand. But it is possible for a human hand to shoot up involuntarily, without the subject acting upon an intention to raise it. And these two sorts of cases - the case of a mere bodily movement and the case of an intentional action - can be indistinguishable from one another. So how can I know that the other is really acting on an intention, i. e., that is his movements are genuine expressions of agency, rather than the mere effects of biological (or psychological, or some other sort of) causes beyond his control. The gap that the Cartesian seeks to bridge here is between a merely bodily movement and the intention that lies beneath (or behind) it. This version of the Cartesian skeptic asks: How can I get beyond an intervening set of bodily events (whose etiology is explicable in, say, purely physiological terms) and arrive at knowledge of the intentions which gave rise to them?

The Cartesian skeptic about intentional action has a problem of the following form: what must I add to a mere bodily movement in order to turn it something which can support knowledge of intentional action. The Cartesian epistemologist's analysis of the situation of the agent turns here on a particular way of conceiving wherein the distinction consists between a bit of genuine agency and a mere bodily movement. Both cases are again conceived as sharing something in common - a highest common factor - in this case the mere bodily movement. 
Any case of intentional agency is then analyzed as a case of a mere bodily movement being preceded by an intention which is then assigned to it as its cause. Thus the Cartesian philosopher of action is forced to grapple with the question of what is left of an intentional action once we subtract the mere bodily movement (on the model of what is left of a case of genuinely veridical sensory perception once we subtract the mere appearance, etc.). This triggers the search for the suitably connected something extra which must be linked to the bodily movement, so that the conjunction of bodily movement supplemented with that extra element can yield a case of intentional action.

It is instructive to consider a final case of the Cartesian problematic, this time from the field of aesthetics. Skeptical problems in the realm of aesthetics are particularly interesting because the feedback loop between theory and practice in the contemporary sphere of the arts is of a sufficiently direct nature that it is possible to find any number of cases in which instances of the practice of art itself has come to reflect the philosophical assumptions implicit in a skeptical understanding of what art is. Philosophical reflection in this sphere is no longer on a set of practices for making knowledge-claims whose self-standing nature as a practice is able to continue unaffected by the character of such forms of reflection. ${ }^{13}$ The following might therefore strike one as equally aptly expressing either a general (and thus contentious) philosophical conception of what art is or a fairly banal description of the self-understanding implicit in certain forms of avant-garde artistic practice:

5. Cartesian skepticism about art. While working at home, I have accidentally turned over a can of paint, creating a pattern of splatter across a piece of canvass that happened to be lying on the ground below the can. From one point of view, what we now have is a waste of some perfectly good paint and a perfectly good canvass. But, let us imagine that downtown, in the Museum of Modern Art, there happens to be hanging on the wall a canvass, sensuously indistinguishable from the one before me, but it bears the caption "Splatter, Artist: James Conant". The object in the museum is declared by the curators of that institution to be a work of art. From an epistemological point of view, apart from their respective locations, one in my home and one in the museum, the two objects seem to be

13 Similar examples of such a feedback loop between epistemic practice and skeptical theory could be adduced from other areas of human life, such as, for example, from the relation between the practice and theory of law. 
indistinguishable from one another. How can I tell which of them is a mere accident and which is a work of art? Andy Warhol's Campbell's Soup Can (or, if you prefer, Marcel Duchamp's Urinal, to take the other favorite example of philosophers of art) seems to be an example of an artifact indistinguishable from one which I might encounter in my own home. But if I cannot tell what distinguishes what is my home from what is in the museum in such a case, then how can I ever claim to know whether something is really a work of art? The gap that the Cartesian seeks to bridge here is one between objecthood and art - between the mere physical appearance of the work of art and its status as a locus of aesthetic value, as something that invites and merits the sorts of interest and assessment appropriate to works of art. So this version of the Cartesian skeptic asks: How can I get beyond the mere objecthood of the work (whose characteristics are describable in purely physical, aesthetically neutral terms) to the art?

\section{Five Examples of Kantian Skepticism}

Again, I begin with the classic case of the genre: (what I call) Kantian skepticism about perception. Again, as before, the first task here is to come to appreciate how the case given below represents just one instance of a far broader genre:

1. Kantian skepticism about perception. How can my senses so much as present things as being a certain way? How can my experience so much as be intelligibly of an external world? The Kantian problematic in philosophy of perception is focused on the problem how the senses must be so as to be able to furnish testimony. An outer object's impinging on the senses would appear, as such, to be a mere transaction in nature, and, taken in and of itself, not to be the sort of item that is "about" anything, let alone the sort that ought to provide anyone with a reason for believing anything. What sort of unity must an episode of sensory experience possess in order to be able to present an appearance about which the question could arise "Shall I endorse it"? The Kantian paradox lies in its coming to seem a mystery how what impinges on my senses could so much as appear to be revelatory of the world. How am I so much as able to enjoy an experience that possesses a determinate world-di- 
rected content (e.g. that I am here in my dressing-gown, sitting by the fire)? The gap the Kantian seeks to overcome is from sensory blindness to sensory consciousness - from a form of sensibility upon which things merely causally impinge to one upon which things impress themselves as being thus and so.

Here what was previously taken for granted by the Cartesian, namely, that there is a determinate way which things appear to me to be in perception, has come under question. The question now is how such an appearance is so much as possible. If we think of the Cartesian question in the philosophy of perception as focusing on the topic of how I can know which of my perceptions are veridical, then it can help to see the issue in Kantian skepticism as turning on the topic of how one of my perceptions can so much as be non-veridical. The very possibility of non-veridicality or falsity in thought, judgment, experience, requires the possibility of an intentional relation between the thought, judgment, experience and reality; the Kantian question is how such a relation is so much as possible.

Under the pressure of a parallel Kantian question, each of the further following four counterparts to the examples of Cartesian skepticism which we encountered above can be identified in the four further areas of philosophy we considered above:

2. The problem of other minds. This version of the Kantian skeptic is preoccupied by the following question: How can the human body so much as seem to express a mental state? A human body is, as such, nothing but so much bio-matter - i.e., a kind of substance whose possible states, taken in isolation, are without psychological purport. So how can any particular state of such a body itself possess the sort of significance we attribute to it when we take ourselves to see that someone is in pain, or happy, or angry. The Kantian paradox here lies in its coming to seem a mystery how an expanse of fleshy matter could so much as appear to be revelatory of an inner life. The Kantian problematic here is focused on the question: How does the human body even seem to furnish a picture of the human soul? The gap the Kantian seeks to overcome here is from an inexpressive physical entity to an animated field of human expression - from a psychologically-neutral locus of bodily movements to the communicative body of a palpably suffering, desiring, pondering human being. 
3. Philosophy of language. This version of the Kantian skeptic is preoccupied by the following question: How can a sequence of marks or noises so much as seem to mean something? Marks and noises are, as such, mere physical entities, devoid of any semantic content. How could such entities, in and of themselves, ever be the sort of things that mean something? The Kantian paradox here lies in its coming to seem a mystery how a mere sequence of dead signs could so much as appear to be alive with significance. The Kantian problematic here is focused on the question: How does a linguistic performance acquire the physiognomy of meaning? What sort of unity must a linguistic performance possess in order to appear to be the sort of thing about which the question could arise "Is this what it means"? The gap the Kantian seeks to overcome here is from meaningless sequences of marks and noises to determinate expressions of thought - from a semantically neutral concatenation of scratches or sounds to a legible field of intelligible meanings.

4. The problem of intentional action. This version of the Kantian skeptic is preoccupied by the following question: How can a mere bodily movement, qua merely physiological event, ever be the expression of an intention? The bodily movement is an event in the natural world and, as such, the effect of purely physiological causes. How can there be any sort of internal relation between such a transaction in the natural world (which is, taken in itself, explicable in purely non-intentional terms) and something that supposedly happens in the mind (an event of an intrinsically intentional character)? The Kantian paradox here lies in its coming to seem a mystery how mere bodily movements could so much as possibly seem to be expressions of genuine full-blooded agency. The Kantian problematic here is focused on the question: How does the execution of a sequence of such movements acquire the physiognomy of an intention? What sort of unity must such a sequence possess in order to appear to be the sort of thing about which the question could arise "Is this what he intended to do"? The gap the Kantian seeks to overcome here is from the movements of muscles, tissues, and limbs to determinate expressions of human willing - from an intentionally neutral concatenation of jangling bodily appendages to a legible field of purposeful human action. 
5. The philosophy of art. This version of the Kantian skeptic is preoccupied by the following question: How can a mere configuration of clay or bronze, or paint on canvass, or sequences of tones, ever so much as seem to be a structure of aesthetic significance and value? Are not such configurations of matter or sound, as such, mere physical shapes or noises which are, considered in and of themselves, devoid of aesthetic value? However fantastically improbable it might be, couldn't, in principle, any such configuration come into existence simply as the consequence of a bizarre sequence of physical events? And, as such, wouldn't such a mere effect of natural causes, absent some further intervening moment of human activity (which aspired to confer significance upon the configuration in question), remain something less than a work of art? How can such mere configurations of matter and sound ever be the sorts of thing that are properly supposed to possess the features we take ourselves genuinely to be able to discover in works of art? The Kantian paradox here lies in its coming to seem a mystery how a mere sequence of shapes and sounds could so much as appear to be alive with aesthetic significance. The Kantian problematic here is focused on the question: How does an object acquire the physiognomy of aesthetic depth? What sort of unity must it possess in order to appear to be the sort of object about which the question could arise "Is this an original work or merely derivative?", "Does it move me (or speak to me or provoke me) or just leave me cold (or chagrined, or disgusted)?", or even just "Does this object merit this sort of critical interest and attention"? The gap the Kantian seeks to overcome here is from aesthetically inert constellations of matter and sound to objects that are properly taken to invite and support forms of aesthetic appreciation and criticism - from artistically neutral chunks of stuff or noise to delightful or provocative exemplars of beauty and sublimity.

Each of the five varieties of skepticism above involves a problematic of a similar form - (what I call) a Kantian form. Identifying a particular variant of a skeptical problematic as being of this form is a matter of recognizing it as sharing a structure with each of the variants of Kantian skepticism presented above. Beginning with the immense amount of attention paid to the third case - Kantian skepticism about language which gained prominence in the $1970 \mathrm{~s}$ and $1980 \mathrm{~s}$, over the past few decades, this has increasingly become the form which so-called "skeptical" problems in philosophy now tend to exhibit. 


\section{Homology of Structure of the Variants within a Variety of Skepticism}

I could go on and multiply pairs of examples of these varieties of skepticism from other areas of philosophy. I take it that variants of both Cartesian and Kantian skepticism arise in ethics, aesthetics, philosophy of law, philosophy of mind, philosophy of science, philosophy of mathematics, etc. ${ }^{14}$ The foregoing five pairs of cases should suffice, however, for the purpose of furnishing a preliminary overview of the twin problematics that I am seeking to isolate here.

This brings us to the first form of philosophical insight that a perspicuous overview of various kinds of skepticism affords. It allows one to command a clearer view of the sorts of relations of symmetry and asymmetry that obtain among variants within a single variety of skepticism. If one commands a clear view of the homology of structure exhibited, for example, across the three variants of Cartesian or Kantian skepticism mentioned above, then one puts oneself in a position to bring resources derived in the consideration of one of these variants to bear on the consideration of others. It is quite remarkable, for example, how many a philosopher today is clear that, whatever else she wants to do in philosophy, she wants to find a way to resist the Cartesian assumption in the philosophy of perception that all perception of external objects

14 I say "variants" of each of these varieties of skepticism arise in each of these "areas" of philosophy (rather than "a variant" of each arises) because in "areas" such as ethics and philosophy of science - "areas", that is, that involve a tangle of different sorts of philosophical problem - a multiplicity of variants of each variety are to be found. Indeed, in both ethics and philosophy of science, for example, a version of each of the philosophy of perception variants and each of the philosophy of language variants of skeptical problematic (along with a great many others) are to be found. This furnishes yet a further reason why one ought to be suspicious of the idea that one should be able to limn the skeleton of philosophy at its joints merely by effecting a division into areas based solely on differences in subject-matter - ethics, science, mathematics, etc. An extended discussion of the topic of the unity of philosophy is well beyond the scope of this paper. It is, nonetheless, a topic that should be on the mind of any reader who thinks that there is little intellectual cost to the increasing specialization of philosophy into supposedly distinct sub-areas (such as philosophy of science, philosophy of language, moral philosophy, etc.) - especially one who thinks that each of these areas requires a specialized form of professional expertise that can be largely acquired in relative ignorance of what goes on in other areas of philosophy. 
requires an inference from how things seem to how things are. She wants to avoid such an assumption because she realizes she will then be saddled with a Cartesian gap (leaving herself sealed inside her own mind, unable to claw her way back out to an unobstructed glimpse of the external world). Yet this same philosopher, when she turns, say, to the philosophy of language yields to the corresponding Cartesian temptation without a pang - finding utterly innocent the assumption that all understanding presupposes interpretation - thus saddling herself with a gap of a homologous sort (leaving herself sealed within a horizon of interpretations, unable way to claw her way back out to an unobstructed grasp of the meaning of an expression).

The first step in learning to attain an overview of the problems in this "area" of philosophy known as "the problem of skepticism" is to learn to achieve a sensitivity to the forms of homology in structure that supposedly distinct philosophical problems in supposedly distinct areas of philosophy exhibit. One must learn to discern when and how the form of the problem has gone unchanged, even though the clothing in which the problem is dressed up has been changed.

\section{Is Kantian Skepticism Really a Form of Skepticism?}

I purported, in originally furnishing ways one might unpack the difference between Cartesian and Kantian skepticism, to be offering various ways of unpacking the contrast between a problematic centered on knowledge and one centered on the conditions of knowledge. This way of putting the contrast makes it seem as if what were at issue were two forms of epistemological worry. As, however, should already be evident from the foregoing, this is quite misleading. It is, indeed, constitutive of the Cartesian problematic that it be clothed in epistemological form. The focus in the Cartesian problematic is on knowledge claims. The Cartesian problematic brings the relation between our knowledge claims and reality into question. What makes someone such-and-such a sort of Cartesian skeptic is that he is exercised by a doubt regarding whether we can have knowledge of such-and-such a sort. Given the internal relation between the concepts of doubt and knowledge, the Cartesian skeptic is quite aptly characterized as someone who doubts. What figures in the Cartesian problematic as a worry about the relation between knowledge claims and reality comes to look, however, from the vantage point of the Kantian problematic, like only an instance of 
a more general worry, a worry about the relation between any claim (true, false or fantastic) and reality. In making a claim at all, whether or not one thereby takes oneself to be knowledgeable, one makes oneself answerable to how things are. The Kantian asks: How is one able to accomplish this feat? The Kantian problematic is therefore only optionally clothed in epistemological form. It is, at its root, of a more general nature. The worry that exercises such a skeptic is misunderstood if it is taken to turn exclusively on matters having to do with knowledge. What comes into view in a Kantian problematic under the initial heading of "the conditions of the possibility of knowledge" are the conditions of the possibility of mindedness as such. Kant himself, with some frequency, alternates between characterizing the sorts of conditions at issue here as conditions of the possibility of knowledge and as conditions of the possibility of experience. (And he implies that they might equally aptly be characterized as, among other things, conditions of the possibility of objectively valid judgment, and conditions of the possibility of sensory consciousness of an object.) The Kantian skeptic is therefore only inaptly characterized as someone who suffers from a doubt. And this will seem to some philosophers to constitute a sufficient ground for insisting that what I am calling "a Kantian skeptic" is not a kind of skeptic at all. So let me be clear on the following point: My aim here is never to legislate how the word 'skeptic' should be used, but only to illuminate some of the diverse ways in which philosophers, in fact, often use it - with the eventual aim of permitting the formulation of the following question: how are these various problematics (each of which is often called one of "skepticism") related? ? $^{15}$

15 Since it will seem to some philosophers simply perverse of me to use the term 'skepticism' in connection with what I am calling "Kantian skepticism”, given my present insistence that what is at issue au fond in Kantian skepticism is not an epistemological worry, perhaps I should briefly say, by way of defense, in anticipation of the remainder of this paper, the following: if one insists upon restricting the application of the term 'skepticism' to overtly epistemological contexts, one is going to be unable to track much that is at issue when the term is employed by Kant, by Wittgenstein, and by many contemporary philosophers. Consider, for example, the debate about the rule-following considerations and the threat of so-called meaning skepticism. What is often at issue in that debate is not just how one can know what something (or someone) means, but how it is so much as possible to mean anything at all. The term 'skepticism' in that debate often names the paradox that ensues if we cease to be able to make sense of the phenomenon in question as something that is so much as possible. What threatens to lapse here is not just our epistemic access to meaning but the very 
Despite having just now acknowledged a perfectly good reason for wanting to resist the invitation to call (what I have been calling) "Kantian skepticism" a variety of skepticism at all, I will continue thus to refer to it. As I go along, I will touch upon some of the reasons why some philosophers have been drawn to project the term 'skepticism' into contexts exhibiting the earmarks of a Kantian problematic and why I think there is a point to following their lead. As will become clear, whether a given philosopher will be inclined to look favorably upon such an extension of the term is not a matter that can be adjudicated on philosophically neutral grounds: which fork in the terminological road one finds less philosophically obfuscating here will depend in large part upon one's collateral philosophical commitments. ${ }^{16}$

Indeed, the question of whether Cartesian and Kantian skepticism, as I have been allowing myself to call them, are properly conceived as two species of a broader philosophical genus of problem (so that the term "skepticism" therefore denotes some fundamental dimension of philosophical concern of which they both partake) or whether the Cartesian and Kantian case, as described above, have little to do with one another as forms of philosophical problem (so that the term "skepticism"

being of meaning. In reply to this, someone might want to insist that, if that is so, then that is a good reason for not employing the term 'skepticism' in the context of that debate. Perhaps so. My point, at the moment, is simply that if one wants to track how the term is often used by many philosophers, one needs to see that it sometimes ranges over philosophical contexts wider than the merely epistemological. Admittedly, this oscillation between a narrowly epistemological and a broader Kantian use of the term makes for many confusions; and it is natural to think the short way to avoid such confusions is to initiate an act of linguistic legislation that restricts the permissible use of the term. But it is too early in our inquiry to adjudicate how the use of the term ought to be restricted, if at all. In order to see how the term is best used, first we need to see more clearly how it is used and why it has come to admit of the variety of uses it presently does.

16 To be more precise: I do not think any particular collateral philosophical commitments need be in place in order to distinguish between those philosophical problematics that bear (what we can call - leaving the term 'skepticism' to one side for a moment) "Cartesian features" and those that bear "Kantian features" respectively. A philosopher's willingness to look upon these as equally instances of something that is properly termed a skeptical problematic, however, may turn on such commitments, especially if what is at issue is the following more pointed question: To what degree is the term 'skepticism' across its employment in Cartesian and Kantian contexts to be understood univocally (rather than as a mere homonym)? 
is really just a homonym when employed in these two cases) is itself a philosophical question. One of the aims of this essay is to attract interest in this question. But we will only be in a position to pose this question, regarding the relation between these two philosophical problematics, once we have each properly in view. It is therefore in order that we first introduce some further conceptual tools which permit us to identify when we are faced with the one problematic and when with the other, and when perhaps with both or neither.

\section{Some Features of the Cartesian Genre of Skepticism}

In order to allow for a more fine-grained discrimination of these varieties of skepticism, I will now proceed to distinguish nine generic features of Cartesian and Kantian skepticism respectively. ${ }^{17}$ But before I do this, let me caution that a considerable element of idealization is involved in the idea of a philosophical problematic characterized by either of the sets of features adumbrated below. ${ }^{18}$ There are two independent dimensions of idealization at work here. The first dimension lies in the idea that a fully realized variant of, say, Cartesian skepticism will exhibit all nine of the mentioned features. It is an idealization because most philosophical discussions that exhibit any one of the features (drawn from one of the two above lists of features) will not necessarily exhibit all of them (though it will probably exhibit many of them). Thus it should be understood that, henceforth, when I speak of "a Cartesian problematic", I will mean a philosophical discussion that exhibits at

17 The point of specifying such features is to furnish criteria for determining which sorts of philosophical rehearsals count, according to the taxonomy introduced here, as cases of one or the other of these varieties of skepticism. In distinguishing these nine features, I do not mean to be doing more than offering a rough and ready characterization of the differences between these two varieties of skepticism. In particular, I do not mean to claim either that each of these features is equally distinct from the other eight or that this set of nine features exhausts the significant features that characterize either of these varieties of skepticism. (Indeed, I think both of these claims are false.) But I do hope that these features suffice to allow one to inspect a philosophical discussion of some topic and determine whether it qualifies as participating in one or the other of the two varieties of skeptical problematic at issue here, and, if so, which one.

18 As I employ the terms, 'Cartesian skepticism" and "Kantian skepticism' denote ideal types of philosophical problematic that are instantiated with varying degrees of faithfulness in any given actual philosophical discussion. 
least a large number of the Cartesian features specified below, but not necessarily all of them. (The more of these features a given philosophical under discussion exhibits, the more Cartesian the problematic in question is.) And, similarly, when I speak of "a Kantian problematic", I will mean a philosophical discussion that exhibits at least a large number of the Kantian features specified below. (The more such features a philosophical problematic under discussion exhibits, the more Kantian it is. $)^{19}$ The second dimension of idealization concerns the way in which the presentation of these feature-spaces may appear to preclude the possibility of their overlap - to preclude an intermingling of Cartesian and Kantian features within a single philosophical problematic. That is both a desirable and a potentially misleading aspect of the presentation that follows. It is desirable in as much as it is part of my aim to illuminate something about the internal structure of each of these two (admittedly idealized) varieties of philosophical problematic. Each has its own logic. The co-occurrence of such features within a single philosophical discussion is generally (though not necessarily ${ }^{20}$ ) a symptom of philosophical confusion on the part of an author; and it is part of my purpose to facilitate the diagnosis and treatment of such forms of confusion. Nevertheless, it is potentially misleading because - even if, in a resolutely executed philosophical inquiry, Cartesian and Kantian features will tend to drive one another out - in the irresoluteness of actual philosophical practice, such features can often be found squashed up against one another. ${ }^{21}$ Borrowing some terms from Cavell's theory of genre ${ }^{22}$, one

19 I, do not mean hereby to rule out cases of philosophical discussion that do perfectly exemplify, without blemishes, either the Cartesian or Kantian format respectively, but only to indicate that they are surprisingly rare.

20 For it not to be a symptom of (at least some degree of) confusion on an author's part requires, I think, that the author already have thought through - and thus have come to some stable view of his own concerning - the relation between these two varieties of skepticism. There are such authors; but not many.

21 For example, in his book Kripke (1982), Saul Kripke initially presents his motivating example in terms that alternate between a Cartesian worry ("How can I know whether in the present case someone is adding or quadding; and if do not know this, then [given that this would appear to be a best case of knowledge of addition] how can I ever know if anyone is really adding?") and a Kantian worry ("How can there ever so much as be a fact of the matter as to whether someone is adding; and, if there cannot then [given that this would appear to be as elementary a case as there can be of someone meaning one thing rather than another] how can anyone ever so much as determinately mean anything?”). This alternation between Cartesian and Kantian idioms has confused some of 
might say that Kantian skepticism represents an adjacent genre of skepticism - one in which each of the features of Cartesian skepticism is displaced $^{23}$ in a certain way. And, just as different genres of film (say, a western and a romantic comedy) can be crossed with another - often (though not always) with aesthetically jarring results - so, too, these genres of skepticism can be crossed with another. In philosophy, when this happens, usually (though not always) it is a sign that the author is no longer clear which of these two philosophical problematics he wishes to inhabit.

The pair of reasons for calling the first set of features "Cartesian" and the second "Kantian" is perfectly consistent with noting the presence of a problematic in Descartes's writings exhibiting some of the features of the second sort (and such a problematic is present in Descartes) and with noting the presence of an aspiration in Kant's writings to address a problematic exhibiting all of the features of the first sort (and such an aspiration forms a crucial part of Kant's project). I denominate these problematics "Cartesian" and "Kantian" respectively, in order to mark not the point of their earliest philosophical inception (the moment at which the seeds of the problematic first began to blossom philosophically) nor their last philosophical flicker of life (the moment past which they cease to have philosophical currency), but rather the historical moment at which their overall philosophical shape first became visible (the moment at which the problematic first reaches full philosophical flower). I denominate the first problematic "Cartesian" because it is in Descartes's writings that it comes fully into view for the first time as one

Kripke's commentators (who equate skepticism with Cartesian skepticism and therefore cling to the Cartesian formulation because it strikes them as more properly skeptical), thus obscuring their view of the problematic that is at the center of Kripke's concern and leading them to waffle alternately between the Cartesian and Kantian variants of skepticism in philosophy of language distinguished above, without ever noticing that they thus waffle. Kripke himself, however, is - at least in certain places in his book (see, for example Kripke (1982), 21) - fairly clear that ostensibly Cartesian characterizations of the issue (according to which, as he says: "the problem may appear to be epistemological") can serve him only as a provisional expository device (thus he says: "the ladder must finally be kicked away") for leading people into a skeptical paradox of an altogether different and more fundamental variety than that with which we appear to be presented if we restrict ourselves to such Cartesian characterizations.

22 See his Cavell (1981) and his Cavell (1996).

23 Cavell's term for this is negated. 
possessing all nine of the features specified below as Cartesian; and I denominate the second "Kantian" because it is in Kant's writings that it first comes fully into view as one possessing all nine of the features specified below as Kantian.

(1) With these cautionary remarks to be borne in mind, I will henceforth refer to the following nine generic features of the Cartesian genre of skepticism as Cartesian features:

(2) The Cartesian investigation begins with and turns on the exploration of a certain sort of example - a best case of knowledge.

(3) Such a case is shown to be vulnerable to doubt.

(4) The conclusion generalizes - we can move from a conclusion about this particular candidate item of knowledge to a general conclusion about all such items.

(5) The investigation thereby issues in a discovery.

(6) The investigation ends in a mood of disappointment.

(7) The disappointment is born of the impossibility of showing how what we had taken to be possible could be actual.

(8) It looks as if there is something we cannot do.

(9) Our inability is the consequence of the existence of a Cartesian gap - a gap we seem to be unable to bridge.

(10) The skeptical discovery cannot be converted into practice: it is practically unstable - we are obliged to live as if we could bridge the gap in question.

First feature. To say that an exploration of the Cartesian problematic begins always with "a best case of knowledge" is to say that it begins always with a carefully selected example - one that possesses (or at least appears able simultaneously to possess) at least the following four characteristics. First, the example must involve a concrete claim to know: a particular person, at a particular time and place must enter the claim. Second, the claim in question must be able to serve as an exemplar of an entire class of claims: it must be sufficiently representative so that each of us can rehearse a version of such a claim in the privacy of our own epistemological closet. Third, the claim must be directed at an unremarkable object - the sort of object which requires no special sort of expertise in order to be able to tell one when you see one. ${ }^{24}$ Thus (what one might

24 The Cartesian skeptical recital always begins by inviting us to direct our attention at a hat, a hand, a chair, a tomato, an envelope - something with regard to which we are all equally experts. As Austin notes, the Cartesian philosopher, 
be tempted to call) "a kind of object" figures in Cartesian examples - a hand, a tomato, an envelope, a chair (but never a nine iron, an M-16 rifle, a Japanese beetle, a goldfinch, or a bubble chamber). One must begin with the right sort of example, in order to get the Cartesian problematic up and running. (Stanley Cavell suggests we call the sort of object that figures in such examples a generic object. We will return to this suggestion.) Fourth, the object must be encountered under optimal conditions: in good lighting, at short range, for an extended period of time, etc. An important part of exploring the Cartesian problematic lies in exploring the character and the legitimacy of the examples employed to introduce a Cartesian skeptical recital and ascertaining whether they really do simultaneously possess all four of the required characteristics. A preoccupation with such examples is a hallmark of the Cartesian problematic.

Second feature. The Cartesian paradox results from the susceptibility of the existence of such an object to doubt. The Cartesian investigation initiates an inquiry into the question what (in our experience of the relevant phenomenon) does and does not admit of the possibility of doubt. It thereby seeks to decompose our experience into two sorts of elements: those which are inherently indubitable and those which involve some (even if perhaps minimal) element of risk. The viability of the ensuing doubt lies in the disclosure of a reliance (on the part of the candidate claim to knowledge) upon those strata of our experience involving this identifiable element of risk. An exploration of what is (and what is not) susceptible to such forms of doubt is a hallmark of the Cartesian problematic. And, under the pressure of the Cartesian investigator's demand for certainty, it leads to the discovery that very little in our experience is invulnerable to such forms of doubt.

Third feature. The possibility of such a discovery depends on the capacity of the initially selected example to generalize. If we don't know this, then we don't know anything. That is, in the disclosure that this particular claim to knowledge is vulnerable to doubt, we do not merely take ourselves to learn that we are not able to know a particular thing that we might have thought we did know. ("Oh, O.K., I guess I don't know that is a goldfinch after all.") Rather we take ourselves to learn something about knowledge as such - or at least about a whole

like the magician, begins by asking us first to be sure that what we have before is nothing other than a perfectly ordinary hat, a perfectly ordinary chair, etc. (Austin (1979), 87). 
class of knowledge claims. ("If I don't know that there is a tomato in front of me right now, then how can I be said to know anything or at least anything based on the testimony of my senses.") The vulnerable of our initially selected example to doubt seems, at one and the same time, to disclose the vulnerability of vast portions of our supposed edifice of knowledge. Thus Descartes does not conclude: "Well, then I don't know that I am sitting here in my dressing gown by the fireplace, after all" Rather Descartes finds himself threatened with a far more general conclusion of the following sort: "Well, then I can never know that things are as my senses tell me they are." An apparently irresistible yet extraordinarily precipitous step of this sort - moving from a finding about a particular claim to knowledge to a general conclusion about the very possibility of knowledge of a certain sort - is a mark of entanglement in a variant of the Cartesian problematic.

Fourth feature. The possibility of such a doubt seems to yield a discovery. The skeptical discovery takes the form of seeing through the surface of our practices to how they really are. For the results of the Cartesian investigation seem to stand in sharp conflict with our ordinary ways of talking and living. Our practices of entering knowledge-claims seem to be fundamentally at odds with what it is that the investigation shows we are really entitled to claim. So, even if the Cartesian inquirer finds himself unable to do other than to continue to speak with the vulgar and to participate in ordinary ways of speaking and acting, nonetheless, in the light of his discovery, these practices must now seem to him to rest upon a tissue of illusion. To the extent that the Cartesian acquiesces in the conclusion his investigation seems to force upon him, he thereby takes himself to be able to see more clearly and deeply into the true nature of these practices than the majority of his fellows who unreflectively participate in them. The attainment of a discovery that seems to unmask our practices in such a manner is symptomatic of entanglement in a variant of the Cartesian problematic.

Fifth feature. The initial thrill of discovery gives way to a mood of disappointment with knowledge. There no longer seems to any way for knowledge (or, within a given variant of Cartesian skepticism: knowledge of a certain sort) to live up to its name. And this gives rise to a mood of disillusionment. One takes oneself to have an understanding of what would have had to have been the case for knowledge (or knowledge of a certain sort) to have been possible. But it transpires that, at least for beings such as ourselves, that possibility is not attainable. One is thus left with the feeling that there is something that ought to 
have been possible but which, as it happens, turns out, at least for us, not to be possible. (The mood of Cartesian skepticism is that of the heroes of Shakespeare's tragedies: one of disappointment at being fated to live in a world that will necessarily betray one's trust in it. ${ }^{25}$ ) Such a prevailing mood of disappointment or disillusionment as the apparently inescapable response to philosophical inquiry is symptomatic of entanglement in a variant of the Cartesian problematic.

Sixth feature. The disappointment lies in our not being actually able to do something that we had always taken to be possible (we are unable to know that things are as they appear). The world we had pre-reflectively taken ourselves to inhabit - a world in which we were capable of attaining knowledge of a certain sort - threatens to turn out not to be the world we actually inhabit. We can formulate thoughts about what such a world would be like and can perhaps still enjoy experiences that purport to be of such a world, but we now are no longer able in our reflective moments to endorse the contents of such thoughts and experiences.

Seventh feature. The structure of the situation we inhabit therefore now seems to come into view as one in which we cannot do something we want to be (and pre-reflectively thought of ourselves as fully) able to do. The skeptical discovery seems to disclose a limit to our cognitive abilities - a limit that kicks in at a far earlier point in the cognitive process than we, prior to our philosophical investigation, had any reason to expect. This sense that, in our philosophical inquiry, we run up against such a limit or barrier that we cannot penetrate or circumvent, try as we might, is a mark of entanglement in a variant of the Cartesian problematic.

Eighth feature. This inability is taken to be a function of our inability to bridge a certain sort of gap. In the case of philosophy of perception, the gap looms between my inner life and the outer world; in the case of other minds, it opens up between his outer behavior and his inner life; etc. The Cartesian takes himself to have made a genuine discovery in having disclosed the existence of such a gap. Cartesian strategies for finding a way around the Cartesian paradox involve attempts to find a way to live with this gap. The Cartesian who wants to avoid a skeptical conclusion wants to be able to negotiate his way across the gap. (Descartes himself famously looked to God for some assistance in this mat-

25 The internal relation between Cartesian skepticism and Shakespearean tragedy is explored by Stanley Cavell in the essays collected in his Cavell (1987). 
ter.) But the gap itself is one he still takes to be just there. As long as one operates within the confines of the Cartesian problematic, the only possible form of "solution" to the problem of skepticism lies in attempting to construct some such sort of bridge across the gap. I will henceforth call the sort of gap at issue here a Cartesian gap.

Ninth feature. The Cartesian inquirer will wish to distinguish theoretical doubt from practical doubt. His doubt, he will tell us, is a merely theoretical one. Though, as such, it represents, he will insist, a perfectly intelligible outcome to an intellectual inquiry; nevertheless, he will also insist, conviction in such a conclusion cannot be sustained by someone caught up in the midst of a practical situation. Cartesian skeptical doubt thus possesses an inherent instability due to the impossibility of its realization in practice. Indeed, we are often reassured by philosophers who wish to introduce us to this problematic that the Cartesian inquiry is one that can and should be suspended for practical purposes. ${ }^{26}$ Such reassurances presuppose the standing possibility of practically abstaining from one's skeptical surmise and re-embracing the modes of experience, thought and expression thereby brought into question. Such an insistence upon the purely theoretical character of the generality of the form of doubt that is at issue in philosophical inquiry is a hallmark of the Cartesian problematic.

26 For most everyday purposes, we cannot and should not try to do otherwise than to take the perceptual appearances that present themselves to us - say, the sudden appearance of an oncoming car - to constitute genuine instances of perceptual knowledge. The Cartesian skeptic knows this. He knows that we cannot help but take someone writhing in pain to be in pain; we cannot help but take certain ossified habits of interpretation to disclose the meaning of a sign; etc. If he understands the structure of the Cartesian problematic, he will not take such observations to impugn his procedures. Some philosophers have thought - and have thought that later Wittgenstein thought - that such observations themselves could suffice to overturn such forms of skepticism. That is a misunderstanding of Cartesian skepticism - and a misunderstanding of Wittgenstein's understanding of it. This is not to deny that such observations (or "reminders", as Wittgenstein preferred to call them) might have a role to play in the treatment of Cartesian skepticism. 


\section{Some Features of the Kantian Genre of Skepticism}

Kantian skepticism can be differentiated from Cartesian skepticism by noticing that it does not quite share any of the above nine generic features. Kantian genre of skepticism exhibits instead the following nine Kantian features - each of which involves a peculiar displacement or reversal or inversion of the corresponding Cartesian feature:

(1) It is constitutive of the sort of investigation into knowledge that it is that it is characterized by a peculiar sort of indifference to the character of the object it takes up as an example.

(2) It does not issue in a doubt, but a boggle.

(3) The paradox is not the result of moving from a conclusion about a particular object to a general conclusion about all objects of experience, but rather a result of the inability to see how there could so much as be an experience that purports to be of a particular.

(4) The investigation climaxes not in a sense of discovery, but one of mystery.

(5) This investigation ends in a mood not of disappointment, but of despair.

(6) The despair is born not of the impossibility of showing how what we take to be possible could be actual, but of showing how what we take to be actual could be possible.

(7) It no longer looks as if there is something we cannot do, now it looks as if there is nothing to do (not even dream) where we had previously thought there was something.

(8) The apparent disintegration of this something into a nothing is the consequence of a Kantian gap.

(9) The Kantian skeptical surmise is not merely practically unstable, but theoretically unstable qua surmise.

First feature. To say that it is constitutive of the Kantian problematic that it is characterized by the absence of a special category of example is to say no more or less than what Kant means to say when he says that transcendental logic, though it does not abstract entirely from objects, is concerned only with the conditions of the possibility of the pure thought of an object: with what it is for thought to be able so much as to be able to have a bearing on the world, what it is for our thought to be related to objects ïberhaupt. Transcendental logic must abstract from all differences between objects - from what it is to be cognitively related to this rather than that sort of object - but not from relatedness to an 
object as such. The two sides of the Kantian problematic, in its classical formulation, turn on how sensibility can yield deliverances that are of objects and how thought can be directed at a (mind-independent) world. The problematic that unfolds here homogenizes the field of possible examples. The questions "What is it to dream that I am in front of a fireplace?" and "What is it to see a fireplace in front of me?" become simultaneously problematized and equally urgent. The questions "What is it to know that I am now in Auburn, Alabama" and "What is it to think of a celestial city?" become equally urgent. The differences between such kinds of example (which play such a crucial role in the context of the Cartesian problematic) cease to be relevant. ${ }^{27}$ It is no less a problem for the Kantian to understand how we are so much as able to think thoughts that are false than it is to understand how it is that we are able to think thoughts that are true. The examples occurring in explorations of the Kantian problematic therefore often exhibit a curiously schematic character: they lack the concreteness of their Cartesian counterparts - not only in the sense that they come in for less determinate characterization, but also in the comparative lack of specification of the epistemic standing of the claim under investigation or of the cognitive attitude adopted towards it. ${ }^{28}$

Second feature. Under the pressure of the Kantian question, all our cognitive capacities (the capacity to doubt among them) come to seem equally questionable. Having worked his way far into a particular

27 More precisely: the differences between these sorts of examples cease to be relevant for the bulk of the Kantian inquiry. At a late stage in the inquiry, it will become important to a Kantian inquirer to recover these sorts of differences differences that underwrite the movement of thought in a Cartesian investigation - but only once the Kantian paradox has been averted and the intelligibility of object-directed thought and experience no longer stands under threat.

28 It does not disrupt the recital of the Kantian problematic - as it would the Cartesian - for the object in question to be of a less than utterly unremarkable sort (a goldfinch can serve the Kantian as well as a tomato) and for no assurances to be forthcoming concerning the epistemic conditions under which the object is encountered. (The lighting, etc., for the Kantian, just has to be good enough to afford some view of the object in question). Early on in the Kantian inquiry, what matters is how we are so much as able to schematize the deliverances of our senses into something that has the determinate character of an appearance - the appearance of, say, a tomato before us. It is a further and comparatively peripheral question, for the Kantian, under what conditions we should or should not endorse the content of such an appearance - and thus judge there to be a tomato before us. 
philosophical dialectic, the Kantian skeptic comes to an impasse: it suddenly no longer seems to him possible that one should be able so much as to frame thoughts that are about the world (or to experience another's bodily movements as expressions of emotion, or to traffic in forms of words that are replete with meaning, etc.). This sort of skeptic becomes perplexed as to what it is to be experiencing or thinking or meaning things in ways that he also cannot help but take himself to be doing in and through the very act of asking his skeptical question. To move in the direction in which his question leads is apparently to deprive his question (along with the whole of the rest of his "thought") of the capacity to possess determinate content. And yet he is unable to dismiss his question. It has come to seem intellectually compulsory. So his mind boggles. Such a boggling of the mind, in the face of a looming conclusion that can neither be approached nor avoided - neither fully comprehended nor simply dismissed on the grounds of its incomprehensibility - is a mark of entanglement in a variant of the Kantian problematic.

Third feature. What is at issue in the Kantian problematic is the possibility of making claims in general, not knowledge claims in particular. This means that the point of departure for a Kantian investigation is not a particular case of knowledge, but rather the topic of the vulnerability of our thought to reality. This, in a certain sense, reverses the direction of the Cartesian investigation: The Kantian paradox is not the result of moving from a conclusion about the character of our experience of a particular case to a general conclusion about all objects of experience, but rather a result of inability to see how there could so much as be an experience which purports to be of a particular. To respond to the Kantian skeptic is to show how our thinking can have a sort of dependence on the world that allows our activity of making claims to come intelligibly into view as one of claim-making at all. In the absence of an adequate response here, the world threatens to recede from our grasp - to the point where not only do we have reason to fear, with the Cartesian skeptic, that we are unable to know which of our claims about it are true, but rather - to the point where we can not any longer even make sense of the idea that we are able to enter claims about anything of a sufficiently determinate character to be either true or false. This sense of the fading away of the possibility of determinate empirical content in our thought, experience, and discourse is a mark of entanglement in the Kantian problematic.

Fourth feature. We can only discover that which we can think. The Cartesian investigation can issue in a discovery, because the Cartesian 
takes himself to be able to form a stable conception of that which he discovers we do not have. The Kantian paradox takes the form not of a discovery, but of a mystery. In each of the three variants of Kantian skepticism briefly sketched above, I characterized the Kantian paradox in question as one in which the possibility of a sort of appearance usually taken for granted in the corresponding variant of Cartesian skepticism suddenly comes to seem mysterious. The Kantian paradox regarding perception lies in its coming to seem to me a mystery how what impinges on my senses could so much as appear to be revelatory of the world. The Kantian paradox regarding other minds lies in its coming to seem a mystery to me how the inert fleshy matter comprising his body could so much as appear to be revelatory of his inner life. The Kantian paradox regarding meaning lies in its coming to seem a mystery how a mere sequence of dead signs could so much as appear to be alive with significance. This sense of our ordinary cognitive capacities as being intolerably mysterious - and therefore calling for a philosophical project that relieves our discomfort by providing an account of these capacities that drains them of their mystery - is symptomatic of entanglement in the Kantian problematic. ${ }^{29}$

Fifth feature. If such a Kantian investigation (into the very possibility of our being able to frame thoughts, enjoy experiences, express meanings, etc.) ends in skeptical paradox, the resulting mood is not one of disappointment - for disappointment (like discovery) is only possible where some glimmering of what it is that one wants (but cannot have) is also available to one. Kant says (concerning what he calls) skepticism, that it is a "way of thinking, in which reason moves against itself with such violence, that it could never have reason arisen except in völliger Verzweiflung of achieving satisfaction with respect to reason's most important aspirations". ${ }^{30}$ The violence with which here, in what Kant calls skepticism, reason turns against itself is a violence of the most ex-

29 Hence, in recent years, the increasingly important relationship between various sorts of philosophical project calling for some sort of naturalistic reduction, on the one hand, and the Kantian problematic in philosophy, on the other. The demand for such reductions in the absence of a plausible program for their execution can, on the one hand, give rise to the relevant sense of mystery; while a philosophically independently fueled sense of Kantian paradox can, on the other hand, fuel the sense that a program of naturalistic reduction is the only possible form of solution to the most urgent philosophical problems that face us today.

30 Kant (1997), 4:271. 
treme possible sort. What reason questions is itself. Our faculty for rational thought arrives at the point where it asks itself (not just how this or that cognitive capacity is possible, but) how it itself is possible, questioning the possibility of the exercise of the very capacity exercised in the framing of such a question. This question is one reason would be driven to pose only if it found itself in a state of völliger Verzweiflung complete desperation or despair - we might say: despair born of desperation. (The mood of Kantian skepticism is that of the heroes of Kafka's parables: one of bewilderment at the dissolution of the world's conditions of intelligibility. ${ }^{31}$ ) Such a prevailing mood of despair as the outcome of philosophical inquiry is symptomatic of entanglement in a variant of the Kantian problematic.

Sixth feature. When reason thus questions its own possibility, the natural history of reason enters a new and radical stage - a skeptical paradox of a different order from the Cartesian is broached. The problem is no longer to understand how something we took to be possible can be actual. The problem is now one that threatens the entire array of cognitive capacities which the Cartesian skeptic takes to be unproblematically available: the capacities to doubt and dream, to feel and think and believe, to enjoy sensory impressions of fireplaces and frame hypotheses about evil demons. The problem now is to understand how something that we take to be actual - for example, the exercise of those cognitive capacities evidently actualized in our philosophical reflections (reflections that themselves seek to address the question of the possibility of such capacities) - can be possible. ${ }^{32}$

Seventh feature. This collapse of the space of possibilities leaves it looking not - as in the Cartesian case - as if there is something we cannot do. Now it looks as if there is nothing to do (not even to dream)

31 I explore the engagement with a philosophical problematic of this sort in Kafka's parables in Conant (2001).

32 There is a joke - which I first heard from Dan Dennett - that goes as follows: "Scientists are the sort of people who, once they see that something is possible in principle, want to know whether it is possible in practice. Philosophers are the sort of people who, once they see that something is possible in practice, want to know whether it is possible in principle." In order to bring out its pertinence to the topic at hand, we might reformulate the joke in even starker terms as follows: "Scientists want to know whether something possible is actual. Philosophers want to know whether something actual is possible." Dennett intended the joke, I think, as a swipe at a certain sort of philosopher. But the joke neatly sums up an important yet elusive aspect of a certain sort of philosophical problematic - the one at issue in this (sixth) Kantian feature. 
where we had previously thought there must be something. The Kantian skeptical discovery, rather than disclosing a boundary which our cognitive abilities run up against, seems to deprive us any territory through which such a boundary might be able to run. This sense that, in our philosophical inquiry, we have found a way to make the Cartesian limit disintegrate (though at the possible cost of ceasing to be able to make sense of our lives) is symptomatic of entanglement in the Kantian problematic.

Eighth feature. The Cartesian takes himself to run up against a gap in his philosophizing (a gap between mind and world, between the body of the other and his soul, between interpretation and meaning, etc.). He takes himself to have made a genuine discovery in having disclosed the existence of such a gap. The gap itself is just there. The Kantian also seems to encounter a certain sort of gap in his philosophizing (between sensory blindness and sensory consciousness, between an inexpressive expanse of mere flesh and the animated field of an expressive human body, between meaningless sequences of marks and noises and determinately meaningful expressions of thought, etc.). But it is not clear what it would be acquiesce in the existence of his gap. It must already be bridged (as evidenced by his present ability to exercise his capacities for perception, expression, and thought); and yet, as long as the threat of Kantian paradox has yet to be averted, it also appears that there is no way to bridge the gap. Thus the Kantian problematic tends to be most lucidly adumbrated in the writings of kinds of Kantian who aim to show that where we seem to be confronted with a Kantian gap, we are confronted with only the illusion of a gap.

Ninth feature. If, as was said above, the philosophical outcome that now looms is one that threatens the array of cognitive capacities which the Cartesian skeptic takes to be unproblematically available (the capacities to doubt and dream, to feel and think and believe, to enjoy sensory impressions of fireplaces and frame hypotheses about evil demons), then the full import of Kantian skeptical paradox must remain intellectually unschematizable. There can be no such thing as getting "it" fully into focus, for getting things into focus seems precisely to be just a further instance of the sort of thing which we now seem bound to conclude we are unable to do. The Kantian worry is not merely (like the Cartesian one) a form of philosophical perplexity that ceases to be sustainable when the attempt is made to translate it into practice. It cannot even be sustained at the level of theory. The practical possibility of abstaining from the modes of experience and thought and expression 
that are here brought into question is not an option that can present itself even momentarily as a live one. This form of skeptical paradox is therefore not unstable merely in the way the Cartesian one is (i. e., because we cannot sustain our conviction in it, as we leave the closet of our philosophy and immerse ourselves in the practical exigencies of life), the Kant paradoxical surmise already occupies a state of radical instability qua surmise. The Kantian skeptic finds himself drawn to a question he is both unable to hold stably in his mind and yet unable to dismiss.

\section{The Inflection of Philosophical Vocabulary in Cartesian and Kantian Registers}

This brings us to the second form of philosophical insight that a perspicuous overview of various kinds of skepticism affords. It allows one to distinguish some of the very different sorts of things philosophers may take themselves to mean when they employ vocabulary such as 'skepticism', 'skeptical paradox', etc. Moreover, which register - Cartesian or Kantian - a philosopher is operating in will also determine the manner in which a great deal of the rest of his philosophical vocabulary is inflected. Equipped with the preceding overview of Cartesian and Kantian features, it becomes possible to survey the history of twentieth-century analytic philosophy and to notice that philosophers (in their discussions of what they call 'skepticism') often tend to be preoccupied with one of these two registers to the exclusion of the other. Most of the mainstream of analytic philosophy has been obsessed with the Cartesian problematic. Moore, Russell, Broad, Ayer, Price, and Chisholm are among the most distinguished members of this Cartesian branch of the analytic tradition. But there is also a branch of the analytic tradition that, though it has fewer members, is equally as distinguished, and occupies itself almost entirely with the Kantian problematic. It includes among its members C.I. Lewis, Wilfrid Sellars, and Peter Strawson. If one then examines how a great deal of philosophical vocabulary ('experience', 'epistemic', 'object', 'the given', etc.) is employed, one notices that it acquires a very different inflection in the writings of one of these sets of authors than it acquires in the writings of the other. A preoccupation with a Kantian problematic characterizes the work of a philosopher such as Heidegger no less than it does that of a philosopher such as 
Sellars. Thus, armed with the distinction between these two varieties of skepticism, one can also notice points of affinity and divergence across the alleged divide between analytic and Continental philosophy. This can provide philosophically far less superficial categories for sorting philosophers into groups than those we usually rely upon. (One can learn to see past the common philosophical reference points and superficial similarities in philosophical tradition and style that unite thinkers such as Heidegger and Sartre, on the one hand, and Wilfrid Sellars and H.H. Price, on the other, and begin to discern certain fundamental divergences, thus enabling one to notice fundamental philosophical affinities between thinkers from different traditions, allowing one to sort together Heidegger and Sellars, on the one hand, and Sartre and Price, on the other.)

Not only individual bits of vocabulary but whole phrases, clauses, sentences and questions acquire a different philosophical valence depending upon whether they occur in the context of the investigation of a Cartesian or a Kantian problematic. Thus, for example, the question "Can our cognitive powers reach all the way to the objects themselves?" can express a Cartesian anxiety about the existence of a gap between our representations of outer objects and those outer objects themselves (the anxiety here is that our cognitive powers always operate at an awkward remove from the objects they represent) or it can express a Kantian anxiety about our capacity to direct our thought at objects (the anxiety here is that our so-called cognitive powers are unable to furnish us with anything which even amounts to a "representation".) Since the same form of words can, on a particular occasion, express either a Cartesian or a Kantian anxiety, it becomes possible, as we shall soon see, for two philosophers to take themselves to be in agreement with one another when they are not, or to take themselves to be in disagreement with one another when they are not. It thus becomes important, when seeking to identify the sort of philosophical problematic in which a philosopher is entangled, to look beyond the most superficial features of a his work, such as the forms of words that he is drawn to employ when framing his problem. One must look instead to the character of the features that characterize his problematic. One philosopher may adopt another philosopher's mode of speaking wholesale and yet miss his problematic entirely. ${ }^{33}$

33 Conversely, one may resolutely avoid a particular philosopher's ways of speaking as a strategy for avoiding his problems and yet end up mired in precisely the 
Even if one confines one's survey of varieties of skepticism solely to noting the presence or absence of only the first of the nine generic features mentioned above (i.e., to noting the character of the examples that figure in each of these two varieties of skepticism), that alone ought to suffice to make one begin to wonder whether Price, Ayer and Austin might not, for the most part, be participating in a tradition of thought about skepticism very different from the one that runs through the writings of Heidegger and Lewis and Sellars. (This is, of course, not to deny that Lewis and Sellars ultimately wish to address some of the concerns of a Price or an Ayer, anymore than it is to deny that Kant ultimately wishes to address Descartes.) A pair of passages from Price and Lewis respectively will serve briefly to illustrate the point.

In these passages, Price and Lewis are each concerned to isolate a certain stratum or strand of our experience - one which they each call the "given" (thus illustrating that the term "given" functions very differently in the context of a Cartesian and a Kantian investigation). First, here is Price's tomato:

When I see a tomato there is much that I can doubt. I can doubt whether it is a tomato that I am seeing, and not a cleverly painted piece of wax. I can doubt whether there is any material thing there at all. Perhaps what I took for a tomato was really a reflection; perhaps I am even the victim of some hallucination. One thing however I cannot doubt: that there exists a red patch of a round and somewhat bulgy shape, standing out from a background of other colour-patches, and having a certain visual depth, and that this whole field of colour is directly present to my consciousness. What the red patch is, whether a substance, or as a state of a substance, or an event, whether it is physical or psychical or neither, are questions that we may doubt about. But that something is red and round then and there I cannot doubt. Whether the something persists even for a moment before and after it is present to my consciousness, whether other minds can be conscious of it as well as I, may be doubted. But that it now exists, and that $I$ am conscious of it - by me at least who am conscious of it this cannot possibly be doubted. And when I say that it is 'directly' present to my consciousness, I mean that my consciousness of it is not reached by inference, nor by any other intellectual process ... nor by any passage from sign to significate.... This peculiar and ultimate manner of being present to con-

philosophical problematic one sought to avoid. This is part of the reason why Richard Rorty's preferred strategies for dissolving philosophical problems tend to be so ineffectual. 
sciousness is called being given, and that which is thus present is called a datum. $^{34}$

Now here is Lewis's fountain-pen:

At the moment, I have a fountain pen in my hand. When I so describe this item of my present experience, I make use of terms whose meaning I have learned. Correlatively I abstract this item from the total field of my present consciousness and relate it to what is not just now present in ways which I have learned and which reflect modes of action I have acquired. It might happen that I remember my first experience of such a thing. If so, I should find that this sort of presentation did not then mean "fountain pen" to me. I bring to the present moment something which I did not then bring; a relation of this to other actual and possible experiences, and a classification of what is here presented with things which I did not then include in the same group. This present classification depends on that learned relation of this experience to other possible experience and to my action, which the shape, size, etc. of this object was not then a sign of. A savage in New Guinea lacking certain interests and habits of action which are mine, would not so classify it.... In whatever terms I describe this item of my experience, I shall not convey it merely as given, but shall supplement this by a meaning which has to do with relations, and particularly with relation to other experiences which I regard as possible but which are not just now actual.... The infant may see it much as I do, but still it will mean him none of these things I have described it as being, but merely "plaything" or "smooth biteable". But for any mind whatever, it will be more than what is merely given if it be noted at all. ${ }^{35}$

One of the things one can say about Price's tomato can, with equal justice, be said of both Price's tomato and Lewis's fountain-pen: Price's expression, "When I see a tomato" has the force of "whenever I see any object". But another of the things one can say of Price's tomato does not hold of Lewis's fountain-pen: the entire existence of the world is squeezed into that tomato. That is to say, Price's tomato and Lewis's fountain-pen each aspire to be in some way representative of the object of knowledge as such. Each of these examples aspires to a sort of generality, but not the same sort.

Price's tomato seeks to represent the object of knowledge as such in virtue of its alleged optimality - in virtue of the supposition that if knowledge fails here it will fail everywhere. Price's tomato is selected as a best case of knowledge and the point of rolling it on to the scene is to see what in one's experience of it is susceptible to doubt, what

34 Price (1932), 3.

35 Lewis (1929), $49 \mathrm{f}$. 
isn't, and what the consequences of such doubt are. Its capacity for representativeness therefore turns on its being a fully determinate case of knowledge. Its representativeness is a function of the way it allows us to infer something about knowledge in general from a consideration of this particular case of knowledge. (Many of the deeper investigations into the Cartesian paradox therefore probe whether there is a tension in the Cartesian skeptic's desire to furnish an example of knowledge that is supposed to be at one and the same time fully representative of knowledge as such and yet a fully determinate instance of a knowledge-claim.) Lewis's fountain-pen seeks to represent the object of knowledge as such in virtue of its exhibiting general characteristics which any instance of empirical knowledge must possess - in virtue of the supposition that all knowledge possesses a common structure and therefore this instance of knowledge must possess that structure. Lewis's fountain-pen is selected not as a best case of knowledge, but as a coherent candidate for knowledge. It is offered not as an exemplary instance, but merely as a run-of-the-mill specimen of the sort of thing that can figure in a claim to knowledge. What is at issue for Lewis is not the unimpeachable certainty, but rather the bare intelligibility of that with which his experience presents him. His example's capacity for representativeness therefore turns on its being susceptible not to a certain sort of doubt, but to a certain sort of abstraction - an abstraction to which any determinate case of knowledge can be subjected. Its representativeness is a function of the way conclusions about this particular instance of knowledge flow from a consideration of what is constitutive of knowledge in general. (Many of the deeper investigations into the Kantian paradox therefore probe whether the conditions - e.g., the sensible and intellectual conditions - that Kantian skeptics allege to be constitutive of knowledge as such, and yet which as conceived by the skeptic appear not to be co-satisfiable, are properly conceived by the skeptic.) The existence of the world is not at stake in Lewis's example of an object, though the possibility of its schematizability - its availability to our thought - is. The point of the example is not to inquire into whether we can know that there is a fountain-pen here, but how it is that we are able to apprehend this particular colligation of sense qualities as a fountain-pen. The point of Lewis's fountain-pen is to present something (and, for this purpose, he could have chosen a much less generic object) knowledge of which involves both a contribution of sensibility and a contribution of understanding. The point of Lewis's exploration of his example is not to see what will and what will not withstand doubt, but to isolate the respective 
contributions of sensibility and understanding in our apprehension of the object. Now I do not mean here to claim that Lewis's sort of investigation does not figure in the work of authors oblivious to the possibility of Kantian skepticism. (Descartes's exploration of his example of the piece of wax figures in The Second Meditation precisely as part of an exercise of isolating the respective contributions of the senses and the intellect.) I mean only to claim that if such an example, treated in such a way, is pressed to the point at which it begins to issue in a skeptical problematic, then the ensuing skeptical problematic will exhibit Kantian features.

I have allowed myself, just now, to speak of "Lewis's sort of example". But this way of speaking is potentially misleading. What is at issue here is not (what philosophers usually mean when they talk about) "a kind of object". (Lewis could have chosen a tomato. But he could also have chosen a goldfinch.) Instead of speaking of "Lewis's sort of example", I would have done better to speak of Lewis's manner of taking up an example. Cavell, after introducing the terminology of "generic object" and "specific object" in The Claim of Reason, goes on to caution that these terms should not be taken to mean "that there are two kinds of objects in the world", rather the point of such ways of speaking is to characterize "the spirit in which an object is under discussion, the kind of problem that has arisen about it, the problem in which it presents itself as a focus of investigation". ${ }^{36}$ So, also, when I say that the object at the focus of the Cartesian problematic, call it the Cartesian object, is different from the object at the focus of the Kantian problematic, call it the Kantian object, this is not because there are two different kinds of objects in the world; rather the point is to characterize two different ways of taking up a possible object of experience and investigating the character of the relation that obtains between it and a cognizing subject. The Kantian object is not to be confused with the Cartesian object. ${ }^{37}$ This

36 Cavell (1979), 55.

37 Contrary to what Cavell suggests in various passing remarks, therefore, the Kantian notion of an "object in general" is radically different from Cavell's notion of a generic object. The latter is Cavellian shorthand for the sort of object that figures in a Cartesian skeptical recital; the former is Kantian shorthand for what is left of our concept of an object once it has been subjected to a severe degree of abstraction. The Cavellian locution stands for the notion of a certain sort of actual concrete particular that is only very indeterminately characterized - yet, this indeterminacy notwithstanding, it is still meant to be something that can be exhibited in experience. Whereas the Kantian locution stands for the no- 
does not mean that the Cartesian object is an object which, due to its unusual properties, does not fall under the genus of Kantian object, but rather that the sort of concept of an object that is at issue in each of these skeptical problematics - and the sort of generality that attaches to each of these concepts - is different.

What the example of the pair passages from Price and Lewis respectively are intended to illustrate is the way in which a whole raft of philosophical terminology - of which the term 'object' is meant to serve merely as one representative instance - acquires a new significance when the context of philosophical investigation shifts from the context of a Cartesian to that of a Kantian problematic.

\section{The Kantian Way with Skepticism}

We now come to the third form of philosophical insight that a perspicuous overview of various kinds of skepticism affords. It allows us to see more clearly some of the ways in which philosophers have had something original and penetrating to contribute to an understanding of the sources and nature of skepticism. One way the work of a philosopher can stand out in this regard is in its appreciation of the symmetries and asymmetries that obtain across the variants of, say, Cartesian skepticism. Another way the work of a philosopher can stand out is in its exploration of the connection between Cartesian and Kantian skepticism. There are two classic figures in the history of philosophy whose writings thus stand out - figures who have been concerned to explore the nature and structure of the Cartesian and Kantian problematics alike and, above all, to explore the relation between them. They are Kant and Wittgenstein. One way of plunging oneself into the heart of their respective philosophies - and of measuring the singular achievement of their respective contributions to the history of thought about skepticism - is

tion of a bare abstract concept of a particular - a concept every actual concrete individual equally instantiates and none properly exemplifies. To mistake this Kantian concept of an object for the name of a sort of item that some sort of being could encounter in experience is a mistake Kant himself warns against. The concept that one arrives at through this severe application of the Kantian procedure of abstraction is, as Kant puts it, an "entirely indeterminate concept"; and he warns that fatal confusion results when one "is misled into treating this entirely indeterminate concept ... as if it were a determinate concept of an entity that allows of being known in a certain manner" (Kant (1998), B307). 
to focus one's attention on their respective inquiries into the relation that obtains between these two varieties of skepticism.

This last observation touches directly on a further respect in which my employment of the labels 'Cartesian' and 'Kantian' might seem tendentious. Was not Kant as interested in (what I am here calling) "Cartesian skepticism" as anyone? My invocation of Kant, in calling the second of these kinds of skepticism "Kantian", is not meant to suggest that Kant does not know about or does not care to address Cartesian skepticism. Before turning to the task of clearing up this misunderstanding, it will help to draw a distinction between weaker and stronger senses in which a philosopher might be termed "Kantian".

To be a Kantian in the weak sense - what I will henceforth call mild Kantianism - requires only that one share with Kant a philosophical problem of a certain form; to be a Kantian in a yet stronger sense which I will henceforth call medium-strength Kantianism - requires that one also share with Kant a conception of the form that the solution to such a problem must assume and what the philosophical implications of such a solution are. I take what I have just said to come to the same thing as this: To be a mild Kantian (the only sense of "Kantian" that has thus far been at issue in this paper) is to be someone who finds himself embroiled in some phase of (what I have been calling) the Kantian problematic; to be a medium-strength Kantian involves not merely finding oneself in the predicament of being thus embroiled, but also wishing to implement a very particular philosophical strategy for liberating oneself from such a predicament - namely, the one that Kant himself sought to implement. ${ }^{38}$

I remarked earlier (in my elucidation of the eighth Kantian feature) that the Kantian problematic tends to be most lucidly adumbrated in the writings of kinds of Kantian who aim to show that where we seem to be confronted with a Kantian gap, we are confronted with only the illusion of a gap. The strategy of such Kantians is to find a way to make the seeming gap disappear. Part of the motivation for such Kantians in making their gap disappear is that, in the process, they hope to show that the corresponding Cartesian gap can also be made to vanish. I am taking it that Kant himself was such a Kantian. That is to say, where I have been

38 The proper account of what it is to be a medium-strength Kantian therefore ultimately rests on a detailed reading of the most difficult portions of The Critique of Pure Reason. I will make no attempt to defend such a reading here; but I will, in various ways, presuppose such a reading. 
distinguishing between two problematics, Kant (as I read him), and certain Kantians, will insist that there is only one extended philosophical problematic. I earlier canvassed a reason why someone might not want to call (what I have been calling) "Kantian skepticism" a variety of skepticism at all. We now see a reason why some philosophers will consider what is at issue here a philosophical problematic that is properly subsumed under the rubric of "skepticism": namely, because they think that what is at issue in the Kantian skeptical problematic is a philosophically more perspicuous and resolute understanding of single philosophical anxiety that, as it comes to understand itself better, comes to assume an increasingly radical form - a philosophical anxiety that (both historically and systematically) comes into view (and achieves a comparatively less clear and distinct form of expression) in the initial guise of Cartesian skepticism.

A variant of what I have been calling "Cartesian skepticism" comes in for special treatment in the Critique of Pure Reason under the rubric of idealism. So the first thing to notice here is that when Kant is restricting his attention to (what I have been calling) Cartesian skepticism he does not employ the term 'skepticism'. Idealism, for Kant, centers around a doubt about the existence of mind-independent objects or as Kant sometimes calls them "material objects". (Thus Kant, employing a label that has not found favor with posterity, also refers to this philosophical position as material idealism.) Kant writes: "Idealism ... is the theory which declares the existence of objects in space outside us to be either merely doubtful and indemonstrable, or else false and impossible". ${ }^{39}$ Skeptical doubt here can be directed at the demonstrability of the existence of such objects (and can thus issue in agnosticism about their existence); or it can be directed at whether we can so much as make sense of the idea of such objects (and can thus issue into the material-object counterpart of atheism). Thus Kant distinguishes two species of idealism (he calls them "problematic idealism" and "dogmatic idealism". (He attributes the former to Descartes and the latter to Berkeley.) The former sort of idealist doubts that we are able to attain knowledge of mind-independent objects. The latter sort of idealist doubts that there are any such objects.

The version of idealism that Kant attributes to Descartes, and with which Kant is focally concerned in "The Refutation of Idealism", turns crucially, Kant thinks, on a certain way of drawing the distinction be-

39 Kant (1998), B274. 
tween inner and outer sense. Descartes does not doubt that we have inner sense - that is that we have experiences of objects of some sort. There is a kind of experience that is immune to doubt. The objects regarding which we have such an indubitable variety of experience are all modes of mental substance, res cogitans. Whereas outer objects - modes of corporeal substance, res extensa - figure in Descartes's philosophy as radically dissimilar to inner objects in that their existence is inherently open to skeptical doubt and consequently in need of philosophical demonstration. The inherent vulnerability of Cartesian outer experiences to doubt, according to Kant, is to be traced to the manner in which experiences of outer objects are conceived by Descartes. Outer objects are conceived by Descartes in such a way that they themselves never fall within the immediate purview of experience. They are never experienced immediately, but only indirectly. The only objects of immediate experience are inner experiences. If one wishes to speak of "outer experiences" then, on a Cartesian conception, the only thing that one can mean by such a phrase is a species of inner experience - something that happens in the mind - where the mental happening in question is one that purports to be about what is outside the mind. So-called "outer experiences" are happenings within the mind which involve representations of what is happening outside the mind. A so-called "outer experience" is thus conceived by Descartes to be an inner experience purporting to be both of something outer and caused by the object it is of.

Thus, on Kant's reading of him, Descartes takes the possibility of experience of how things seem outside of us - the possibility of an experience's being thus "about" or "of" something outer - to be a comparatively unproblematic phenomenon. The skeptical problem for Descartes - what Kant calls the problem of idealism - only begins when we turn to the question of how we can reason reliably from how things seem to us to how things actually are outside of us. Thus Kant stresses that the apparent coherence of the idealist's position rests on the presupposition of the apparent coherence of an inference from how things are within the mind to how things are without the mind: "Idealism assume [s] that the only immediate experience is inner experience, and that from it we can only infer outer things - and this, moreover, only in an untrustworthy manner, as in all cases where we are inferring from given effects to determinate causes." ${ }^{40}$ Kant characterizes his argument-strategy in "The Refutation of Idealism" as one in which "the

40 Ibid. B276. 
game played by the idealist is turned against itself', ${ }^{41}$ Kant aims to show that without what the idealist wants to infer to there would be nothing to infer from. To turn idealism's own game against itself is, for Kant, to show "that we have experience, and not merely imagination of outer things"; and Kant thinks that the way to show this is to show that "even our inner experience, which for Descartes is indubitable, is possible only on the assumption of outer experience". ${ }^{42}$ What Descartes takes to be a separable and self-contained realm of experience - the sphere of inner life (the domain of res cogitans) - Kant wants to show to be not in the least self-standing in the way that Descartes imagines it to be. Kant wants to show that the capacity for inner sense is only possible for a being which also already has the capacity to enjoy immediate experiences of outer objects, and, moreover, that these two capacities are not separable in the way Descartes imagines inner and outer sense to be. Rather they are equally constitutive aspects of the unitary consciousness of any being capable of experience. ${ }^{43}$

Kant's argument in "The Refutation of Idealism" itself presupposes the results of the preceding pages of the Transcendental Analytic; and the aim of the Transcendental Analytic, as a whole, is to try to get the Kantian paradox into view and to show how to make it go away. That is to say, Kant's treatment of the Cartesian problematic presupposes his treatment of (what I have been calling) the "Kantian problematic". The question that the Transcendental Analytic seeks to address is: what sort of unity must characterize a play of representations for them so much as seem to be of objects. The decisive step in the Transcendental Deduction lies in showing that a play of representations, for it to have objective purport, must be in accord with the unity that the categories prescribe. In showing that anything worthy of the title of experience must accord with these conditions of unity, Kant takes himself to be addressing someone whom he calls "the skeptic". When, in such contexts,

41 Ibid.

42 Ibid. B275.

43 The argument that inner and outer sense mutually depend upon one another comes in two steps. The argument that all objects - and hence also the objects of outer sense - depend upon the form of inner sense is presented in the Transcendental Aesthetic. This shows that outer experience is only possible on the assumption of inner experience. The Refutation of Idealism shows that inner experience is only possible on the assumption of outer experience. These two arguments jointly show that neither of these two sorts of experience is possible except as part of a larger package which also includes the other. 
we find Kant using the word 'skepticism' what is at issue is a (Kantian) boggle, not a (Cartesian) doubt. Here is an example of such a context:

The concept of cause, for instance, which expresses the necessity of an event under a presupposed condition, would be false if it rested only on an arbitrary subjective necessity, implanted in us, of connecting certain empirical representations according to the rule of causal relation. I would not then be able to say that the effect is connected with the cause in the object, that is to say, necessarily, but only that I am so constituted that I cannot think this representation otherwise than as thus connected. This is exactly what the skeptic most desires. For if this be the situation, all our insight, resting on the supposed objective validity of our judgements, is nothing but sheer illusion. ${ }^{44}$

What is at issue in this passage is not a Cartesian worry (that we might be subject to illusions of knowledge), but rather that we might be subject to an even more radical form of illusion: an illusion of objective purport. In order to understand better who this skeptic is and how he comes to be called a "skeptic", it helps further to distinguish a particular sub-species of the Kantian problematic - which one might call the $\mathrm{Hu}$ mean problematic with regard to causation. One then needs to see how a certain sort of radicalization of the Humean problematic, from the category of cause to the other categories, issues directly into the Kantian problematic. A proper discussion of this topic would require considerably more space and take us well beyond what is required for the purposes of the schematic distinction here at issue between varieties of Kantianism of various strengths.

It will help now to discriminate more finely the possible strengths of Kantianism and to distinguish between medium-strength and (what I shall call) maximum-strength Kantianism. I earlier defined the former grade of Kantianism by saying that it requires that one share with Kant a conception of the form that the solution to the Kantian problematic must assume and what the philosophical implications of such a solution are. To be a maximum-strength Kantian requires not only that one share Kant's philosophical aim and strategy for liberating oneself from the Kantian skeptical predicament, but also to have mastered the requisite nuances of such a strategy to be able to implement it successfully. Since the application of the term "Kantian" in this strongest possible sense thus depends upon the successful execution of a philosophical endeavor, it can remain a philosophically open question whether it is so

44 Kant (1998), B168. 
much as possible to be a maximum-strength Kantian. If one takes it that it is possible (that is, if one is a medium-strength Kantian), but if one's philosophical endeavor fails to live up to its own aspirations (thus placing in jeopardy the possibility of being a maximum-strength Kantian), then one is threatened with a skeptical outcome of a different order from that which seems to threaten the unsuccessful execution of a Cartesian inquiry.

Historically, the possibility of such an outcome first comes fully into view with the possibility of a Kantian response to Kant's own radicalization of the Humean problematic. This opens up the possibility of an investigation climaxing in a form of skeptical paradox of a sort apparently quite distinct from that of the Cartesian paradox. In order to gain a firmer sense of how a distinctively Kantian form of skeptical paradox can come to seem a philosophically urgent matter, it is worth returning for a moment to the case of C.I. Lewis. ${ }^{45}$ Building on his example of the fountain pen, consider how Lewis goes on to argue for his thesis that we must acknowledge a given element in perceptual experience. Lewis's opening moves are unimpeachably Kantian. Lewis starts from the thought that conceptual activity is a form of activity, and as such freely undertaken. Here Lewis is following Kant in taking it that all cognition must involve an element of spontaneity - that element in knowledge which we, as knowers, must freely bring to the world in order for knowledge of it to be a possible achievement for us. But, according to Lewis, this requires that we also recognize a given element in experience something that operates as a constraint from outside on the freedom of conceptual activity - the element in knowledge which we, as knowers, must unresistingly take in from the world in order for our "knowledge" of "the world" to be something more than the contemplation

45 This case is discussed by McDowell in his paper "Putnam on Natural Realism". (McDowell's paper was written and first read by me in or around 1998. It has been forthcoming ever since in the Library of Living Philosophers volume on The Philosophy of Hilary Putnam - a volume which apparently is now scheduled to be published in 2012.) The ensuing discussion of Lewis simply summarizes in McDowell's own language McDowell's treatment of Lewis. It seeks to do so in a manner which brings out as vividly as possible how the climax of Lewis's own Kantian skeptical problematic is of such a sort as to issue in a form of paradox quite different from the Cartesian one. That McDowell's own way of summarizing the upshot of Lewis's Kantianism should be able to bring this point out so vividly itself illustrates how very clear McDowell himself is regarding the differences between Cartesian and Kantian skepticism which form the main topic of this paper. 
of our own reflection, for it to be of something outside us. Here Lewis is following Kant in taking it that all cognition must therefore equally involve an element of passivity. ${ }^{46}$ Without some contribution of spontaneity, the deliverances of our senses would be mere impacts - as Kant says: blind - less even than a mere dream. But, on its own, the mere activity of thinking is empty - as Kant says: ohne Sinn oder Bedeutung - as long as its play remains unconstrained from without. What Lewis calls "the given" is that which is thus delivered up to the mind, furnishing it with content upon which to operate, thus rescuing its operations from emptiness and arbitrariness. Lewis takes us to have no choice but to acknowledge such a given element in experience, if we wish to frame a conception of what it is to have an empirical world-view according to which (that which we wish to be able to look upon as) our "world-view" amounts to something more than wholly unconstrained fabrication. Indeed, without the constraint of the given, what we are left with is less even than a mere fabrication. For there can only be fabrication where there can be something more; and without any constraint on the operations of our spontaneity, the distinction between mere fabrication and something better lapses. There is no longer any basis for distinguishing between those of our constructions that afford a glimpse of how things are and those that are mere caprice. Without the possibility of drawing a distinction between mere caprice and genuinely world-guided belief, there is no longer anything in our so-called "world-view" that is recognizable as world-directed thought.

Lewis, however, construes the second condition on knowledge in a very particular way and takes himself, in thus construing it, to be following Kant (thereby participating in a long-tradition of "followers" of Kant): he assumes that the freedom of conceptual activity must be seen as constrained from outside its own sphere, if we do not wish to lose our grip on thought's possession of content. Hence Lewis declares not only something Kant would be happy to declare: "If there be no datum given to the mind then knowledge must be contentless and arbitrary; there would be nothing which it must be true to." ${ }^{47}$ But he also

46 It is constitutive of any robust (i. e., non-mild) form of Kantianism that it postulates both of these elements and seeks to illuminate and render intelligible the possibility of their productive cooperation with one another. The difference between medium-strength and maximum-strength Kantianisms tends, above all, to turn on the relative degree of failure or success in rendering these apparently independent conditions on knowledge productively co-satisfiable.

47 Lewis (1929), $38 \mathrm{f}$. 
goes on to declare: "The pure concept and the content of the given are mutually independent; neither limits the other." 48 Lewis insists that the given, qua merely given, must remain utterly uncorrupted by the concepts which we bring to it, on pain of our falling into a vicious form of idealism, in which we are no longer able to see our conceptual activity as constrained by anything from outside its own sphere.

Lewis, however, also needs find a way to allow that the data given to the mind be more than bare and brute. They must be able to "guide" belief. He thus needs also to be able to conceive the postulated given element in experience as such that it be able to direct and underwrite our conceptual activity. So he here finds himself in a bind: the given must be able to "guide" experience without in any way "limiting" it. The given must constrain conceptual activity, while exercising its constraining influence from wholly outside the sphere of conceptual activity. The bind that Lewis finds himself in is that these two requirements on the given are not obviously co-satisfiable. He must locate the given as far enough "outside" the sphere of the conceptual to allow it to serve its function as "external constraint" (keeping our cognitive wheels from spinning in a frictionless vacuum), while placing it close enough "inside" that sphere to permit it to serve its "guiding" function (warranting the application of some of our concepts, while refusing that of others). Lewis is thus faced with the following challenge: How is the given able to offer guidance to our concepts while remaining itself always conceptually unarticulated in nature? Lewis heroically strives to tell a story which allows him to walk this tightrope - a story according to which the given can serve its warranting function in spite of itself being that which by its very nature cannot be captured by concepts. It is to this end that he attempts to draw the distinction between being an instance of a quale and being an instance of a concept. He wants to be entitled to see the former sorts of instances as possessing many of the features that instances of the latter sort possess without themselves being instances of the latter sort. He says (in the fountain-pen passage quoted above) of that which is given in the diverse possible experiences of the fountain pen (i.e., those of the infant, the professor, and the savage) that, qua given, what is "presented" is "a colligation of sense-qualities". ${ }^{49} \mathrm{He}$ wants to be able to say that the same (in some non-conceptual sense of "same") colligation of sense-qualities is presented in each such

48 Ibid. 37.

49 Ibid. 49. 
case; and that it is this that in each guides the use of concepts. This requires that he be able to make sense of the idea that one can recognize (in some sense of "recognize") such colligations as the same without the mediation of concepts. In order to cash out this idea of a non-conceptual mode of recognition, he needs to be able to exploit the implication of universality in the term "qualities" while conceiving the sort of universality here at issue as utterly distinct from the universality of concepts (on pain of having the supposedly "external" constraint collapse into the sphere of conceptual activity). But Lewis is unable to pull off the trick, he keeps falling off the tightrope, with the consequence that the argument of Mind and the World Order, utterly contrary to Lewis's own intention, threatens to collapse into a distinctively Kantian variety of skeptical paradox - one which leaves us unable to make sense of ourselves as so much as in possession of a "world-view".

Lewis is the sort of a medium-strength Kantian who has helped to convince many that maximum-strength Kantianism is unattainable and thus that Kantianism represents nothing more than a philosophical dead-end. It is crucial to a proper understanding of Kant's own way of avoiding the outcome threatening Lewis's inquiry (and thus to an understanding of "Kantianism" in the maximum-strength sense of the term) to see that it is absolutely central to the aim of the Transcendental Analytic not only to show (as Lewis himself seeks to do) that there are these two dimensions of knowledge - sensibility and understanding - each of which is a necessary and neither of which is a sufficient condition of knowledge, but also to show precisely what Lewis imagines he must avoid (on pain of sacrificing the external constraint on knowledge that saves it from being contentless and arbitrary): namely, that these twin aspects of our cognitive constitution - our capacity to receive a sensory impression that things are thus and so and our capacity to direct our thought at an object (real or imaginary) are in no way independently satisfiable conditions on the possibility of knowledge..$^{50}$ On my understanding of what maximum-strength Kantianism entails, what is original in Kant's understanding of the relation between the two varieties of skepticism distinguished above is that he thinks that it is only once you see the way in which the intelligibility of each of these conditions presupposes the other - that is, that it is only once you see (1) what is transcendentally required in order to exercise the capacity to enjoy sense

50 For more on this point, see Thomas Land's contribution in the companion volume to this volume, Rethinking Epistemology vol. 1 (Land 2012). 
impressions that purport to be of something and (2) what is transcendentally required in order to exercise the capacity to entertain thoughts that purport to be about something, and (3) why you can only have one of these capacities if you have both - that you are able to equip yourself with the resources to dispose of the Cartesian skeptic. If the Cartesian skeptic grants, as he must, that he has the resources to enjoy impressions and entertain thoughts - resources required in order so much as to frame his doubt - then, having thought your way through the dialectic of the Kantian problematic, you will be in a position to show him that the gap he seeks to bridge is only the illusion of a gap. Thus, for Kant, the way to handle Cartesian skepticism is not to answer it head-on, but to think through the implications of an even more radical skeptical problematic. In coming to see what is incoherent in Kantian skepticism, we are to come to see what is incoherent in Cartesian skepticism as well. I will call this two-phased approach to the twin problematics of Cartesian and Kantian skepticism the Kantian way with skepticism.

Most readers of Kant utterly misunderstand The Critique of Pure Reason by taking its response to Cartesian skepticism to begin much earlier in the book than it does. And such a misreading of the book is inevitable if one fails to see that the Cartesian problematic represents for Kant only a special case of a more general problematic. Kant's generic term for this more general problematic - of which Cartesian skepticism is eventually to be recognized as only a limiting case - is "skepticism". This furnishes yet another reason why, even if you yourself wish to reserve the term 'skepticism' for a problematic exhibiting characteristically Cartesian features, it is important to be able to realize that in speaking of "skepticism" a philosopher may have (what I have been calling) "Kantian skepticism" in mind: namely, because, unless you allow for this possibility, it will become impossible to see what Kant, and certain Kantians, are up to in their treatments of (what they call) "skepticism".

If one groups together the writings of philosophers who practice something akin to the Kantian way with skepticism, it induces an interesting canon-one which includes, among others, writings as diverse as T.H. Green's critiques of Locke and Hume, Frege's critique of psychologism, early Wittgenstein's attempt in the Tractatus to show that realism and idealism strictly thought through can be seen to collapse into one another, and more recently John McDowell's criticism of Davidson in Mind and World. The positive touchstone of this way with skepticism is a radical following through of the implicit assumptions of a skeptical position up to the point at which the position founders in incoherence. 
The Kantian way with skepticism involves the ascent up a dialectical ladder that one eventually recognizes as one that is to be thrown away.

\section{A Case of Apparent Agreement: Putnam and McDowell}

We now come to a fourth form of philosophical insight that a perspicuous overview of the various kinds of philosophical response to skepticism can afford. A number of the finest contemporary philosophers writing about skepticism today misunderstand one another's writings by trying to shoehorn a skeptical paradox bearing Kantian features into a problematic of Cartesian form and vice versa. As a first example of such a misunderstanding, let us consider a recent misencounter between Hilary Putnam and John McDowell. ${ }^{51}$

In his 1994 Dewey Lectures ${ }^{52}$, Hilary Putnam attempts to identify a widespread assumption that he claims runs throughout early modern philosophy - he dubs the assumption in question "the interface conception" - and he argues that, three centuries later, it continues to be responsible for many of the difficulties that plague contemporary philosophy. Putnam characterizes the consequences of the continuing hold of this assumption on the philosophical imagination of our time as nothing short of a "disaster". His summary statement of how contemporary philosophy managed to place itself in its present disastrous position runs as follows:

[T] he key assumption responsible for the disaster is the idea that there has to be an interface between our cognitive powers and the external world - or, to put the same point differently, the idea that our cognitive powers cannot reach all the way to the objects themselves. ${ }^{53}$

51 My discussion of this example is indebted throughout to John McDowell's paper "Putnam on Natural Realism" mentioned above. This section of my paper contains nothing original that is not to be found in McDowell's beyond the way in which it seeks to show how the disagreement between McDowell and Putnam at issue is usefully reframed in terms of the two varieties of skepticism distinguished above and therefore how the disagreement here is au fond one regarding the relative priority of these two varieties of skepticism.

52 Putnam's Dewey Lectures were given at Columbia University in March of 1994 and first published in Vol. XCI, No. 9 of the Journal of Philosophy. They are reprinted in Putnam's book The Threefold Cord (1999) and all references to them will be to this latter publication.

53 Putnam (1999), 10. 
Putnam here glosses the crucial assumption as follows: "the idea that our cognitive powers cannot reach all the way to the objects themselves". If we could overcome the assumption expressed by these words, Putnam suggests, we would be in a position to embrace with a sound philosophical conscience what Putnam (following William James) calls "the natural realism of the common man". This locution - "natural realism" - as Putnam deploys it, is not meant to be a label for an alternative philosophical position; rather it is meant to denote something both more familiar and more elusive: our own pre-philosophical understanding of the character of our cognitive relation to the world, prior to its corruption by certain forms of philosophizing that have now come to seem to be forms of post-scientific common sense. Thus Putnam is able to describe what he seeks to recommend in the Dewey Lectures as the cultivation of a kind of second naiveté about the objects of perception. But our philosophical consciences are troubled. Putnam knows this, and thus knows that, in issuing his call for a return to a lost state of epistemological innocence, he is bound to appear to many of his colleagues to be merely the most recent incarnation of the proverbial philosophical ostrich burying his head in the sands of our everyday ways of talking and thinking. What makes it inevitable that things will so appear to many of his colleagues, according to Putnam, is the interface conception: it is what makes it look as if the recommended species of naiveté cannot be anything other than mere naiveté. Putnam credits John McDowell, in his book Mind and World, with having identified (what Putnam calls in the passage above) the "key assumption". ${ }^{44}$ But Putnam

54 The context of the previous quotation makes this evident:

Let us now ask just why realism about "the external world" came to seem problematical. Early modern philosophers assumed that the immediate objects of perception were mental, and that mental objects were nonphysical.... What is more, even their materialist opponents often put forward accounts of perception that closely paralleled these "Cartesian" accounts....

In his 1991 John Locke Lectures [published in Mind and World] John McDowell argues persuasively that this picture, whether in its classical version or in its modern materialist version, is disastrous for just about every part of metaphysics and epistemology. In McDowell's view the key assumption responsible for the disaster is the idea that there has to be an interface between our cognitive powers and the external world - or, to put the same point differently, the idea that our cognitive powers cannot reach all the way to the objects themselves (Putnam (1999), 10). 
is here misreading McDowell $;^{55}$ and in order to pinpoint how such a misreading of McDowell comes about, it helps to be able to see, as we already have, how a phrase such as "our cognitive powers cannot reach all the way to the objects themselves" can hover - and does hover on Putnam's pages - between two different sorts of philosophical problematic: a Cartesian and a Kantian one.

To see how Putnam is here misreading McDowell, we need to see how Putnam manages to change the significance of McDowell's prose while often faithfully paraphrasing or quoting McDowell's exact words. We need to see how Putnam's employment of stretches of philosophical prose - prose which he lifts directly from the pages of McDowell's book - does not leave their sense unchanged. By transplanting McDowell's locutions into the context of Putnam's own attack on the interface conception, Putnam confers a sense upon McDowell's locutions different from that which they possessed in the context of McDowell's own investigation. As the context in which the relevant stretches of McDowell's prose figure shifts from the exploration of a Cartesian to that of a Kantian problematic, so does their sense - in ways parallel to the ways in which the central locutions common to both Price's and Lewis's passages above ("object" or "thing", "consciousness", "object", "the given", etc.) shift from the one passage to the next.

A central aim of McDowell's book is to make room for the following truism (one that philosophy can easily seem to place out of reach) which Wittgenstein expresses, in McDowell's favorite quotation from Wittgenstein, as follows: "When we say, and mean, that such-andsuch is the case we - and our meaning - do not stop anywhere short of the fact." 56 This sounds very much like things Putnam himself wants to say, for example, in wishing to affirm that "our cognitive powers can reach all to the objects themselves". In affirming this, Putnam represents himself, in the Dewey Lectures, as spelling out some of the basic ideas behind McDowell's strategy for making room for truisms of the above Wittgensteinian sort. And, of course, the negation of the claim which figures in the last phrase in the above quotation from Put-

55 I do not mean to deny that McDowell is concerned to criticize the interface conception in some of his writings, most notably in his essay "Criteria, Defeasibility, and Knowledge", but only that McDowell would not identify the target of that essay with "the key" confusion that he seeks to exorcize in Mind and World.

56 Wittgenstein (1973), section 95. The passage is quoted by McDowell (1994), 27. 
nam - "that our cognitive powers cannot reach all the way to the objects themselves" - can be taken as merely paraphrasing the same truism that figures in McDowell's favorite quotation from Wittgenstein. It is clear that Putnam, in aligning himself with McDowell, wishes us to take it that way. But it is equally clear that he also wishes us to take the negation of the claim expressed by that phrase as the expression of the repudiation of the disastrous assumption forced on us by the interface conception. It is in wishing to be able to mean words such as these in both of these ways at once that Putnam gets entangled both in his understanding of the structure and aim of the argument of McDowell's Mind and World and in his proposals for a way out of the problems that currently plague contemporary philosophy.

One sign that some slippage has taken place is that the Wittgenstein passage - and McDowell's book generally - is concerned with the possibility of meaning (with the possibility of our being able to mean something - rather than nothing - by our words), whereas much of the Dewey Lectures are focally concerned with the possibility of knowledge (with how it is that we can know things are as they seem). In his opening remarks, Putnam expresses the thought he wants to vindicate in his lectures as follows: "there is a way to do justice to our sense that knowledge claims are responsible to reality without recoiling into metaphysical fantasy". ${ }^{57}$ But from McDowell's point of view, the focus here on knowledge claims (as the paradigm for understanding the kind of responsibility to reality which philosophy brings into question) must count as at best misleading, and at worst misguided. For it invites a misidentification of the strand of philosophy that McDowell is focally concerned to treat: it invites the substitution of a Cartesian for a Kantian problematic. McDowell would, of course, not want to deny that we should view knowledge claims as responsible to reality. But he would want to insist that, for the purposes of his investigation, they constitute only a special case of a more general (Kantian) problematic concerning the possibility of the vulnerability of any claim to how things are. The sort of vulnerability to reality under investigation in his book is exhibited in false claims equally fully as in true ones. The kind of vulnerability to reality at issue in his investigation figures equally in our capacity for thinking (indeed, dreaming) as it does in our capacity for knowing. McDowell's investigation does not single out those of our claims which are knowledgeable because it is concerned with what must be the case for any sort

57 Putnam (1999), 4. 
of human intellectual activity to be intelligible as one of claim-making at all. It is the possibility of making claims in general, not knowledge claims in particular, that comes to seem at risk when our entitlement to the truism in Wittgenstein's remark seems to come under threat.

As he proceeds in his lectures, as we shall see in a moment, Putnam himself describes the issue with which he is concerned in terms that make no particular reference to knowledge, for instance as the "how does language hook on to the world" issue. So it may seem an uncharitable quibble to raise worries about his opening formulation of the issue in terms of knowledge. But the narrowness of the epistemological manner in which he introduces his topic is symptomatic of a disabling unclarity that pervades his lectures - an unclarity regarding the character of the philosophical problematic which he seeks to address. As we saw in the previous section of this paper, the phrase "our cognitive powers cannot reach all the way to the objects themselves" can be inflected in either a Cartesian or a Kantian register. The phrase can be taken to denote the idea of either a Cartesian or a Kantian gap. Inflected in a Cartesian register, the meaning of the phrase can happily be glossed as Putnam glosses it: as "the idea that there has to be an interface between our cognitive powers and the external world". But it is only in its Kantian inflection that the phrase tracks the problematic that stands at the center of McDowell's investigation in Mind and World, and, thus inflected, it cannot simply be identified - as Putnam throughout wishes to identify it - with the Cartesian assumption that there has to be "an interface between our cognitive powers and the external world". It is only through this conflation of the kinds of "responsibility to reality" at issue in Cartesian and Kantian skepticism respectively that Putnam is able to take the diagnosis that McDowell aims to advance in Mind and World to be coincident with the one he himself seeks to advance in the Dewey Lectures. To see this more clearly, consider the following sequence of passages from Putnam's Dewey Lectures:

Let us now ask just why realism about "the external world" came to seem problematical. Early modern philosophers assumed that the immediate objects of perception were mental, and that mental objects were nonphysical.... What is more, even their materialist opponents often put forward accounts of perception that closely paralleled these "Cartesian" accounts. Even in contemporary cognitive science, for example, it is the fashion to hypothesize the existence of "representations" in the cerebral computer. If one assumes that the mind is an organ, and one goes on to identify the mind with the brain, it will then become irresistible to (1) think of some of the "representations" as analogous to the classical theorist's "impres- 
sions" ... and (2) to think that those "representations" are linked to objects in the organism's environment only causally, and not cognitively....

... I agree with James, as well as with McDowell, that the false belief that perception must be so analyzed is at the root of all the problems with the view of perception that, in one form or another, has dominated Western philosophy since the seventeenth century.... The tendency in the last thirty years to repress what continues to puzzle us in the philosophy of perception obstructs the possibility of progress with respect to the broader epistemological and metaphysical issues that do preoccupy us....

... How could the question "how does language hook on the world?" even appear to pose a difficulty, unless the retort: "How can there be a problem about talking about, say, houses and tress when we see them all the time?" had not already been rejected in advance as question-begging or "hopelessly naïve". The "how does language hook on to the world" issue is, at bottom, a replay of the old "how does perception hook on to the world" issue. And is it any wonder if, after thirty years of virtually ignoring ... the task of challenging the view of perception that has been received since the seventeenth century ..., the very idea that thought and language do connect with reality has come to seem more and more problematical? Is it any wonder that one can't see how thought and language hook on to the world if one never mentions perception? ${ }^{58}$

In the above sequence of remarks, Putnam wishes to identify the difficulty posed in the question "how does language hook on the world?" with the difficulty made urgent by the interface conception. Elsewhere in his writings, Putnam is extremely sensitive in his treatment of philosophical problems that bear the earmarks of a Kantian problematic, and in showing how putative solutions to those problems, if strictly thought through, can be seen to collapse into variants of Kantian skepticism. ${ }^{59}$ But in the above sequence, Putnam insists on privileging a Cartesian problematic as holding the key to a diagnosis of philosophy's most fundamental problems. I do not mean to suggest that Putnam is entirely clear or resolute in his Dewey Lectures in his desire to privilege a Cartesian problematic over a Kantian one. On the contrary: as the Dewey Lectures proceed, it is clear that Putnam also wishes to identify the difficulty posed in the question "how does language hook on the world?" with the difficulty (at the heart of much contemporary philosophy of mind

58 Ibid. 9-13.

59 Putnam's criticisms of attempts to naturalize meaning are an example of this. $\mathrm{He}$ sees such views as degenerating into a variant of Kantian skepticism. Putnam is here influenced by certain arguments of Frege's. For a brief discussion of the strain of Putnam's thought that I have in mind here, see my "Introduction" to Putnam (1994), xlii-xlvi. 
and language) which McDowell seeks to address in Mind and World one that, as we saw from our brief discussion of C.I. Lewis, does not fit into a Cartesian mould. It is precisely this irresoluteness on Putnam's part that I am seeking to bring into focus: Putnam wants what is at issue throughout to be the same "how does language hook on the world?" issue. But what I said above about the phrase "our cognitive powers cannot reach all the way to the objects themselves" applies equally to the question "how does language hook on the world?". In the pages of Putnam's Dewey Lectures, these forms of words hover unstably between the expression of a Cartesian and a Kantian worry - and that instability can be resolved only at the cost of depriving Putnam's preferred diagnosis of the source of contemporary philosophy's ills of its intended generality. Putnam's "key assumption" cannot unlock the problems that McDowell seeks to address.

Large stretches of the Dewey Lectures make sense only if the worry expressed in questions such as "Can our cognitive powers reach all the way to the objects themselves?" and "How does language hook on the world?" is taken to be of a Cartesian variety. This is equally true of the entire sequence of passages quoted above; and if that sequence is taken as offering - as it clearly intends to - a diagnosis of most of what ails contemporary philosophy, and if the question at issue is taken to express both the worry made urgent by the interface conception and yet somehow at the same time the one that animates the sorts of philosophical worry McDowell seeks to address in Mind and World, then Putnam may not claim McDowell as an ally. For what Putnam then says in that sequence of passages must be fundamentally at odds with the diagnosis McDowell seeks to put forward in Mind and World. What McDowell will take to be unsatisfactory in Putnam's diagnosis can be put as follows: Putnam, in effect, suggests that the various forms of Kantian skepticism that have come to seem so urgent in recent philosophy can be exorcised simply through the treatment of Cartesian skepticism.

McDowell would want to press the following question: Is Putnam right in claiming that the "how does language hook on to the world?" issue is, at bottom, simply a replay of the old "how does perception hook on to the world?" issue? The correct answer to this question is: it depends on which "how does language hook on to the world" issue is at issue. (As I have indicated above, there is a Cartesian and a Kantian version of the issue.) McDowell would contend that Putnam's claim is not right about the version of the problem that is, for the most part, the 
one that figures at the center of concern in the writings of, for example, Lewis or Sellars or Kripkenstein or Crispin Wright. The Kantian difficulty (concerning the very idea of thought's or language's capacity to be vulnerable to reality) with which each of the aforementioned authors struggles does not, for the most part, have its source in a Cartesian difficulty (concerning the indirect character of all perceptual contact with the "external" world). None of these authors are evidently concerned to urge a version of (what the Dewey Lectures calls) the "received" view of perception; and Putnam's efforts to highlight the dubious assumptions underlying the "received" view do not evidently bear on their problems.

A fourfold worry about the recent turn that Putnam's thought has taken in the Dewey Lectures emerges here: (1) that Putnam in the Dewey Lectures tends to conflate the Cartesian and Kantian varieties of problematic potentially at issue in his discussion, (2) that the problematic that is increasingly pressing in contemporary philosophy is the Kantian one and that Putnam does not seem to be sufficiently cognizant of this, (3) that the difficulties to which that problematic gives rise will not be made to vanish simply by exposing what is dubious in the assumptions of the Cartesian skeptic, and (4) that a satisfying treatment of Cartesian skepticism itself requires that we also think through what is confused in Kantian skepticism. This last claim is central both to Kant's and to McDowell's own Kant-inspired arguments. Once such a fourfold worry about Putnam's procedure in the Dewey Lectures comes into focus, it also becomes possible to see what is misplaced in Putnam's effort to generously credit John McDowell's Mind and World with having furnished the outline of the diagnosis Putman himself seeks to offer in the Dewey Lectures. Although it is true that McDowell, like Putnam, is concerned to vindicate (what Putnam, following James, calls) "the natural realism of the common man", it is not an exaggeration to say that McDowell's diagnosis of the sources of the perplexities with which contemporary philosophy struggles is precisely the reverse of Putnam's most recent one: where Putnam argues that it is only if we think through what is confused in the Cartesian skeptic's question "Do we really see houses and chairs?" that will we free ourselves from the confusions visited upon us by the analytical-Kantian skeptical question "how does language hook on to the world?", McDowell thinks that it is only once we think through what is hopeless about the sort of Kantian bind in which someone like C. I. Lewis threatens to place himself - one in which it is no longer possible to see how thought 
can so much as be answerable to reality - that we will be able fully to free ourselves from Cartesian worries about the character of our perceptual relatedness to houses and chairs. For Putnam, in the Dewey Lectures, the Cartesian paradox is the fundamental source of (what Putnam calls) "the broader epistemological and metaphysical issues" that continue to "preoccupy us" in contemporary philosophy. ${ }^{60}$ For McDowell, in Mind and World, the Cartesian worry is an intelligible, though inept, response to an inchoate form of philosophical anxiety that achieves comparatively fuller expression in the sort of Kantian paradox that, in his view, haunts the projects of authors such as Lewis, Sellars, Davidson and Brandom.

This misencounter between Putnam and McDowell is not atypical. The fourth form of philosophical insight that a perspicuous overview of varieties of skepticism can afford is to help us identify such occasions occasions on which philosophers systematically misunderstand one another's writings: sometimes paying one another undeserved compliments, and at other times going to battle against one another when their views in no way disagree. In Putnam's misappropriation of McDowell's diagnosis of the skeptical paradox that haunts contemporary philosophy, we have a case of merely apparent agreement between two of the finest philosophers of our time. Now let us consider a complementary case - one of merely apparent disagreement.

\section{An Apparent Disagreement: Cavell and Kripke}

Stanley Cavell's The Claim of Reason presents a brilliant account of certain aspects of Wittgenstein's treatment of Cartesian skepticism. Saul Kripke's book Wittgenstein on Rules and Private Language explores certain aspects of Wittgenstein's presentation of Kantian skepticism. Each of these books has a hold of a portion of philosophical territory Wittgenstein is concerned to explore that the other misses. Cavell, however, declares himself unable to recognize the problematic that Kripke calls one of "skepticism" to be a variety of skepticism at all, let alone one in which Wittgenstein should interest himself.

One can take Kripke to have correctly identified the problem which Wittgenstein means to be grappling with the in the sections which run from $\$ \$ 185$ to 201 of the Philosophical Investigations without having to endorse Kripke's suggestions for how to understand Wittgenstein's pre-

60 Putnam (1999), 11. 
ferred response to the (so-called) "rule-following paradox" and especially not his attribution to Wittgenstein of a "skeptical solution" to that (or any other) skeptical paradox. In saying that what Kripke calls "skepticism about meaning" is a species of skepticism which Wittgenstein seeks to treat, I mean to affirm nothing more than that the paradox which Kripke finds in Wittgenstein is one that Wittgenstein seeks to address, that it is only one instance of a broader genre of philosophical paradox, that Wittgenstein throughout his writings is repeatedly concerned to formulate and address paradoxes of this genre, and that such paradoxes are ones that belong to that broader genus of philosophical perplexity that Wittgenstein himself often designates - as did Kant before him through his application of the term "skepticism". (The scope of the term "skepticism" as employed by Wittgenstein is sufficiently capacious so as to encompass both Cartesian and Kantian varieties of skepticism.) The paradox at which Wittgenstein arrives in section 201 of Philosophical Investigations bears all the earmarks of (what I have been calling) a Kantian skeptical paradox; and the dialectic which threads its way through the preceding sections of the Philosophical Investigations is mired in a Kantian skeptical problematic. Indeed, it is the third variant of the Kantian problematic mentioned early on in this paper - the one that centers on the question "How can a sequence of marks or noises so much as seem to mean something?"

Cavell says, in his discussion of Kripke in Conditions Handsome and Unhandsome, that he wishes to "question whether Kripke's examples illustrate skepticism", and Cavell evidently feels that something important about his own reading of Wittgenstein would be threatened by the concession that Kripke's examples illustrate (something that could be called) "skepticism". But this perception on Cavell's part stems from a failure to command a clear overview of the shape of the philosophical terrain here. Armed with such an overview, it becomes possible to see that nothing in Cavell's admirable corpus of work on Wittgenstein would be threatened by such a concession. The term "skepticism" in Cavell's work - and in his writings on Wittgenstein - exclusively denotes a problematic of the Cartesian variety. To concede, however, that Wittgenstein is interested in variants of the Kantian paradox does not gainsay his equally ubiquitous fascination with their Cartesian counterparts. Cavell, in his discussion of Kripke's reading, begins with a surely sound observation - to wit: that what Kripke calls Wittgenstein's "skeptical solution" is not anything Wittgenstein would countenance as a "solution" to a philosophical problem. But Cavell moves precipitously 
from this observation to the conclusion that if Kripke's solution is not Wittgenstein's then "the problem to which Kripke offers the solution is not (quite) Wittgenstein's either". ${ }^{61}$ This is a non-sequitur. The reason I think Cavell feels bound to take this step is because he is quite properly unable to recognize the skeptical paradox of section 201 of Philosophical Investigations to be one that bears (what I have called) Cartesian features. Hence Cavell goes on to remark:

Kripke reports that sometimes, contemplating the situation of discovery that one may mean nothing at all, he has had "something of an eerie feeling" (21), and that "the entire idea of meaning vanishes into thin air" (22). Is this, I ask myself, like the feelings I have had, under a skeptical surmise, of the world vanishing (as it were behind its appearances), or my self vanishing (as it were behind or inside my body)? These feelings have been touchstones for me of skeptical paradox, of conclusions I cannot, yet become compelled to, believe.... I would like to say that when the entire idea of meaning vanishes into thin air what vanishes was already air, revealing no scene of destruction. ${ }^{62}$

One can hear Cavell in this passage - and in much of the rest of his subsequent questioning of "whether Kripke's examples illustrate skepticism" - quite rightly pointing out that Kripke's alleged skeptical paradox bears none of the Cartesian features: it does not begin with a best case of knowledge, the investigation does not issue in a discovery to which one is unable to accommodate oneself, the conclusions that Kripke draws about his examples do not generalize in accordance with the logic of the Cartesian format, etc. I therefore find myself agreeing with everything that Cavell has to say about this, except his conclusion - that is, I agree that the paradox of section 201 is not a Cartesian paradox, but not that it is not a skeptical paradox.

\section{The Wittgensteinian Way with Skepticism}

I said earlier that the positive touchstone of the Kantian way with skepticism is a radical following through of the implicit assumptions of a skeptical position up to the point at which the position founders in incoherence. The negative touchstone of the Kantian way with skepticism is that it seeks to find a way to respond to the Cartesian skeptic that by-

61 Cavell (1991), 69.

62 Ibid. 80. 
passes the task of having to enter into the details of Cartesian examples, exploring how they are motivated, and considering how they differ from ordinary examples of knowledge. We can contrast the Kantian way with skepticism with what we might call the Wittgensteinian way with skepticism. The Wittgensteinian way is not an alternative to, but rather a supplementation of the Kantian way. The difference between the two ways points up what I take to be utterly original in Wittgenstein's later treatment of skepticism and what I take to be utterly absent from Kant's treatment of skepticism. The Wittgensteinian way incorporates a further movement, pushing the skeptic in the opposite direction from the one in which Kant seeks to push him: not only following the skeptic's presuppositions out to their ultimate consequences, but also examining the initial steps in the Cartesian skeptic's progress towards doubt, identifying how the skeptic passes from ordinary to philosophical doubt, from a claim to a non-claim context, pinpointing the decisive movement in the philosophical conjuring trick and diagnosing why it is the one that is bound to seem most innocent. Thus we might say, the Kantian way drives the skeptic forward in his doubt, seeking to propel the skeptic to grace by forcing him to pass through utter despair, whereas the Wittgensteinian way supplements this prospective movement with a retrospective one, leading the skeptic back to the point of entry into his problematic, returning him to the lost innocence of the everyday. The Kantian way compels the skeptic to progress further and further forward, further and further from the ordinary, and deeper and deeper into philosophical perplexity, to an ever more violent form of questioning, to the point at which the skeptic's question consumes itself. The Wittgensteinian way adds to this pressure an additional one that seeks to bring the skeptic back to the place where he started, where he already is and never left, but in such a way that he is able to recognize it for the first time.

These two movements that Wittgenstein's philosophical practice alternately seeks to execute are nicely summarized in the following two remarks:

(1) My aim is: to teach you to pass from a piece of disguised nonsense to a piece of undisguised nonsense. (Philosophical Investigations, section 464)

(2) What we do is to bring words back from their metaphysical to their everyday use. (Philosophical Investigations, section 116) 
I will henceforth refer to these two movements that Wittgenstein seeks to execute as the movement up the dialectical ladder (towards nonsense) and the movement down the dialectical ladder (towards the ordinary). This way of putting things helps to bring out both a fundamental moment of continuity and a fundamental moment of discontinuity between Wittgenstein's early and later philosophical practice. The former of these two remarks could serve equally aptly as a characterization of the aim of the author the Tractatus. The latter could not. What I am here calling "the Wittgensteinian way" is therefore meant to designate a way with skepticism that we first find only when we turn to Wittgenstein's later writings.

We come therefore now to a further aspect of the fourth form of philosophical insight that a perspicuous overview of the various kinds of philosophical response to skepticism can afford. A number of the finest contemporary philosophers writing about skepticism today misunderstand one another's writings by specifically failing to appreciate the complementarity of these two movements in later Wittgenstein's writings, thereby approaching those writings with oppositely occluded blind-spots.

H.H. Price and C.I. Lewis - as we saw earlier - are philosophers who are usefully categorized as a Cartesian and Kantian respectively. Price's thinking moves exclusively within the dialectical space of the Cartesian problematic; Lewis seeks to short-circuit the Cartesian problematic through a prior exploration of the Kantian problematic. John McDowell and Stanley Cavell are, initial appearances to the contrary, philosophers who are not quite so easily categorized. We saw, while reviewing Putnam's misencounter with McDowell, how McDowell wished to privilege the Kantian problematic over the Cartesian one; and we saw in Cavell's misencounter with Kripke how Cavell seemed to want to privilege the Cartesian problematic over the Kantian one. Thus, based on the evidence reviewed thus far, the following conclusion might seem tempting: McDowell is primarily concerned to explore the Kantian problematic and Cavell the Cartesian. And that conclusion, in turn, might pave the way for another, possibly equally tempting one, with regard to how each of these philosophers read Wittgenstein: Cavell and McDowell have complimentary blind-spots in their readings of Wittgenstein - each is relatively sensitive to those stretches of Wittgenstein's writings in which a philosophical problematic bearing one of these sets of features comes in for extended discussion in its own right, and each is relatively insensitive to those stretches of Wittgen- 
stein's writings in which a philosophical problematic bearing the other comes in for extended discussion in its own right. And there is certainly some truth to this.

Cavell is masterful in his exposition of Wittgensteins diagnosis and treatment of the ways in which the Cartesian skeptic is led to speak "outside language-games", but has, for example, little to say that is instructive about Wittgenstein's treatments of the (Kantian) problematics of rule-following and intentionality. McDowell is masterful in his exposition of the winding dialectic of sections 185-201 of Philosophical Investigations and its bearing on the later treatment of, for example, the relation between an expectation and its fulfillment, but has almost nothing to say about the route by means of which the Cartesian skeptic enters his problematic and thus about any of the countless moments Wittgenstein seeks to isolate in which, in our philosophizing, we first begin to lapse into those forms of verbal inflection in which language goes on holiday.

If we look more closely at more of Cavell's and McDowell's respective writings, however, it becomes less tempting to say that each of them is peculiarly sensitive to only one of these problematics at the expense of the other, either in their own work or in their respective readings of Wittgenstein. Each of them is far too attentive a reader of later Wittgenstein to allow a pervasive focus of philosophical concern in Wittgenstein's corpus to drop entirely out of view in their own rendering of Wittgenstein's thought. What happens rather, in their respective writings about Wittgenstein, is that Wittgenstein's exploration of one of these two skeptical problematics tends alternately to come into focus while the other recedes into the background. And, indeed, I think it is almost inevitable that, in working on later Wittgenstein, one should find this happening to one in one's writing about him. To illustrate the point, I will place side by side some further passages from Cavell and $\mathrm{McD}$ owell - passages in which their roles have been reversed now McDowell will appear to be the one more preoccupied by the Cartesian dimension and Cavell by the Kantian dimension of Wittgenstein's concerns. 


\section{A Second Apparent Disagreement: Cavell and McDowell}

John McDowell, in "Criteria, Defeasibility and Knowledge" argues that (what Wittgenstein calls) criteria are internally related to the justification of claims to knowledge in the following way: if a claim to know that such-and-such turns out not to be justified then the criteria for claiming such-and-such were only apparently satisfied. Thus, for example, if you claim that someone is in pain, and it turns out that that person is only pretending to be in pain, then the criteria for pain were only apparently satisfied. Here is McDowell:

Commentators [on Wittgenstein] often take it that the possibility of pretence shows that criteria are defeasible. This requires the assumption that in successful deception one brings it about that criteria for something "internal" are satisfied, although the ascription for which they are criteria would be false. But is the assumption obligatory? Here is a possible alternative; in pretending, one causes it to appear that criteria for something "internal" are satisfied (that is, one causes it to appear that someone else could know, by what one says and does, that one is in say, some "inner" state); but the criteria are not really satisfied (that is, the knowledge is not really available). ${ }^{63}$

Stanley Cavell, in The Claim of Reason, is concerned to challenge almost exactly the same interpretation of Wittgenstein on criteria that McDowell is concerned to challenge and for many of the same reasons. Yet Cavell comes to (what is at least verbally) precisely the opposite conclusion with regard to how to employ the concept of a criterion in connection with the very sorts of examples that McDowell discusses. Thus Cavell concludes that even if someone is only pretending to be in pain, if it is pain that he is pretending to be in, then his behavior satisfies the criteria for pain. Here is Cavell:

[O]nly certain eventualities will count as [someone's] not being in pain... Circumstances, namely .... in which we will say (he will be) feigning, rehearsing, hoaxing, etc. Why such circumstances? What differentiates such circumstances from those in which he is (said to be) clearing his throat, responding to a joke, etc.? Just that for "He's rehearsing" or "feigning", or "It's a hoax", etc. to satisfy us as explanations for his not being in pain ... what he is feigning must be precisely pain, what he is rehearsing must be the part of a man in pain, the hoax depends on his simulating pain, etc. These circumstances are ones in appealing to which, in describing

63 McDowell (1998), 380. 
which, we retain the concept (here, of pain) whose application these criteria determine. And this means to me: In all such circumstances he has satisfied the criteria we use for applying the concept of pain to others. It is because of that satisfaction that we know that he is feigning pain (i.e., that it is pain he is feigning), and that he knows what to do to feign pain. Criteria are "criteria for something's being so", not in the sense that they tell us of thing's existence, but of something like its identity, not of its being so, but of its being so. ${ }^{64}$

The first thing to notice is that McDowell and Cavell appear, at first blush, simply to disagree: in cases of pretending to be in pain, McDowell says the criteria for pain are not satisfied, Cavell says they are. The second thing to notice is that their roles now seem, as promised, to be reversed. McDowell takes Wittgensteinian criteria to operate at a Cartesian level. The question that is settled, according to him, if criteria are satisfied, is one concerning the truth of a claim, the existence of the pain, the reality of the phenomenon. Cavell takes Wittgensteinian criteria to operate at a Kantian level. The question that is settled, according to Cavell, if criteria are satisfied, is not one concerning the truth of a claim but one concerning its purport, not one concerning the existence of something which falls under a concept but the applicability of the concept itself, not one concerning the reality of a phenomenon but one concerning its possibility. Whichever of these two readers of Wittgenstein you take to be on the right track, it is worth noticing that this is the structure of the disagreement here, and that the level at which you take criteria to operate, e.g., in connection with phenomena such as pain, will have decisive consequences for the sort of response to skepticism that will issue from an appeal to "criteria". Now I myself take it that Cavell has got the merely exegetical question right (about what question is settled if Wittgensteinian criteria are satisfied) and McDowell has got it wrong. But I will not argue that point here. (This does not, however, mean that there is any substantive philosophical disagreement between McDowell and Cavell here. ${ }^{65}$ ) What interests me here is the

64 Cavell (1979), 45.

65 Cavell, if he were brought to see how McDowell is employing the term "criterion", could concede, without harm to any of his philosophical commitments, something along the following lines: "Well, that is not how Wittgenstein uses the term; but if you are determined to use the term in this (un-Wittgensteinian) way, then the right (i.e., philosophically Wittgensteinian) thing to go on and say, so using it, is just what you say (e.g., that in cases of pretending the criteria for pain are only apparently satisfied)." And McDowell, equally, if he were taught Cavell's understanding of the term (criteria are not criteria for 
very fact that their disagreement should, at this juncture, have this particular structure. This has a two-fold irony, stemming from the ways in which each of them seems to have given up his previous role in the two misencounters canvassed above.

The first irony is to be found in the fact that in much of his writing about Wittgenstein McDowell reads Wittgenstein as seeking to address Kantian skepticism and in Mind and World follows his Wittgenstein in seeking to take an exclusively Kantian way with skepticism. McDowell tends to see the Cartesian craving for epistemic security as an intelligible, though inept, response to an inchoate form of the philosophical anxiety that only arrives at clear expression when it is posed as a Kantian skeptical paradox. Thus, despite his Cartesian construal of the grammar of the concept of a criterion, McDowell tends to see the treatment of philosophical skepticism as requiring attention only to the Kantian problematic. He assumes, in the manner of Kant himself, not only that the Cartesian skeptical paradox can be shown to be merely a special case of a more general worry, but more importantly that, once this is shown, Cartesianism will be robbed of all its force and will wither away of its own accord without requiring any additional form of specialized treatment.

The second irony to be noted in connection with the structure of McDowell's and Cavell's disagreement about Wittgenstein's concept of a criterion lies in the fact that Cavell, though he is far too acute a reader of Wittgenstein to fail to appreciate that the Philosophical Investigations is frequently operating at a Kantian level, nonetheless, never sees that for Wittgenstein, as for Kant, the term "skepticism" ranges over far

something's being so, but for its being so) would have no reason not to concede that the right thing to say, so using the term, is just what Cavell says (i. e., that in cases of pretending, if it is pain you are pretending to be in, then the criteria for pain are satisfied). The disagreement between Cavell and McDowell about criteria is a further instance of a merely apparent disagreement in which the appearance of disagreement is engendered through an unacknowledged transition from a Cartesian to a Kantian problematic. Both McDowell and Cavell are in profound disagreement with their respective and very similar sets of interlocutors (Baker, Wright, Albritton, Malcolm, etc.), but they are disagreeing with them about different things. (McDowell's point has to do with how justification and knowledge are internally - and not merely externally - related to one another; Cavell's has to do with how an appeal to criteria cannot do the work that Wittgenstein calls upon it to do, if criteria are understood in the manner of such commentators.) Their respective philosophical motivations for disagreeing with such commentators are perfectly compatible. 
more than a merely Cartesian skeptical problematic - thus over far more varieties of philosophical perplexity than a merely Cartesian inflection of the term is able to encompass. Nonetheless, Cavell, through carefully following out the inner movement of the dialectic traced in Wittgenstein's investigations, often finds himself fetching up in the terrain of the Kantian problematic. Here is a characteristic passage that may stand for a thousand others:

If you do not know the (non-grammatical) criteria of an Austinian object (can't identify it, name it) then you lack a piece of information, a bit of knowledge, and you can be told its name, told what it is, told what it is (officially) called. But if you do not know the grammatical criteria of Wittgensteinian objects, then you lack, as it were, not only a piece of information or knowledge, but the possibility of acquiring any information about such objects überhaupt; you cannot be told the name of that object, because there is as yet no object of that kind for you to attach a forthcoming name to. ${ }^{66}$

What is threatened with the loss of (what Cavell calls) Wittgenstein criteria is not merely the possibility of isolating an unimpeachable item of knowledge, but the possibility of so much as turning up a candidate for knowledge. At one point in The Claim of Reason, Cavell quotes the following four passages from Philosophical Investigations in rapid succession:

... [O]nly of a living human being and what resembles (behaves like) a living human being can one say: it has sensations; it sees; is blind; hears; is deaf; is conscious or unconscious. (section 281)

What has to be accepted, the given, is - so one could say - forms of life. (section 226)

What gives us so much as the idea that living beings, things, can feel? (section 283)

The human body is the best picture of the human soul. (section 178)

These are passages in which Wittgenstein presents what Cavell says he understands "as the background against which our criteria do their work; even make sense" ${ }^{97}$. They are also quintessential examples of moments in his work in which Wittgenstein's investigations move (from the Cartesian) to the Kantian level. And, in commenting on these passages, Cavell (taking the problem of other minds here as his example of a skeptical problematic) expresses what he takes to be the significance of such passages in Wittgenstein's work:

66 Cavell (1979), 77.

67 Cavell (1979), 83. 
To withhold, or hedge, our concepts of psychological states from a given creature, on the ground that our criteria cannot reach to the inner life of the creature, is specifically to withhold the source of my idea that living beings are things that feel; it is to withhold myself, to reject my response to anything a living being; to blank so much as my idea of anything as having a body. To describe this condition as one in which I do not know (am not certain) of the existence of other minds is empty. There is now nothing there of the right kind, to be known. There is nothing to read from that body, nothing the body is of; it does not go beyond itself, it expresses nothing; it does not so much as behave. There is no body left to manifest consciousness (or unconsciousness). It is not dead, but inanimate; it hides nothing....

My problem is no longer that my words can't get past his body to him. There is nothing for them to get to; they can't even reach as far as $m y$ body.... The signs are dead; merely working them out loud doesn't breathe life into them; even dogs can speak more effectively. ${ }^{68}$

I take the presence of a Kantian problematic in this passage to be selfevident. Though Cavell in such passages (and there are many such passages in The Claim of Reason) sees that the transition to a Kantian problematic plays an essential role in Wittgenstein's treatment of skepticism, he seems only able to interest himself in this transition to the extent that it forms part of a response to Cartesian skepticism; hence his view of the scope of this problematic in Wittgenstein's writing is artificially blinkered. Central issues - concerning, for example, the nature of the accord between a rule and its application (not only, as in certain employments of the mathematical case, as a trope for learning a word, but as a perplexing instance of the Kantian problematic in its own right), between an expectation or wish and its fulfillment, etc - recede into the background of Cavell's reading of Wittgenstein. This blind-spot in Cavell's reading of Wittgenstein (and in his reading of Kant) comes perhaps most visibly to the surface in his discussion of Kripke's reading of Wittgenstein. Although he sees that Wittgenstein is concerned to explore the Kantian problematic, he does not see (and feels that he must not allow) that it can issue in a distinctive (and, as I have tried to show, distinctively Kantian) variety of philosophical paradox - one that Wittgenstein, like Kant, views as a variety of skepticism. This leaves Cavell's account of Wittgenstein's treatment of skepticism essentially incomplete. Only a reading able to accommodate, both exegetically and philosophically, the insights contained in both Cavell's and McDowell's respective readings of Wittgenstein - that is, only one that understands

68 Ibid. $83 \mathrm{f}$. 
why, in Wittgenstein's treatment of the extended philosophical dialectic of which they each form a part, neither variety of skepticism is to be privileged over the other - will be complete.

\section{Conclusion}

The aim of this paper has been to suggest that a perspicuous overview of various kinds of skepticism and the kinds of response they engender affords a number of different kinds of philosophical benefit: it allows one to command a clearer view of the sorts of relations that obtain across apparently distinct areas of philosophy, it allows one to distinguish the very different sorts of things philosophers mean when they employ (what is apparently) the same philosophical vocabulary (and especially when they employ the word 'skepticism'), it allows one to see more clearly what is distinctive about Kant's and Wittgenstein's respective contributions to the history of thought about skepticism, and it allows one to see more clearly why these authors are often misread and why their best commentators often misread one another and misunderstand themselves - taking themselves to disagree with one another when they do not, taking themselves to agree with one another when they do not, and taking themselves to be in agreement with themselves when they are not. ${ }^{69}$

\section{References}

Austin (1979): John L. Austin, Philosophical Papers, Oxford.

Cavell (1979): Stanley Cavell, The Claim of Reason, Oxford.

Cavell (1981): Stanley Cavell, Pursuits of Happiness, Cambridge/MA.

Cavell (1987): Stanley Cavell, Disowning Knowledge, Cambridge/MA.

Cavell (1991): Stanley Cavell, Conditions Handsome and Unhandsome, Chicago.

Cavell (1996): Stanley Cavell, Contesting Tears, Chicago.

Conant (1992): James Conant, “The Search for Logically Alien Thought: Descartes, Kant, Frege and the Tractatus", in: The Philosophy of Hilary Putnam, Philosophical Topics 20 (1), 115-180.

69 As should be evident to anyone familiar with their work, this paper is pervasively indebted to the writings of Stanley Cavell, John McDowell, and Hilary Putnam. A much shorter version of this paper was published in Wittgenstein and Skepticism, edited by Denis McManus. 
Conant (2001): James Conant, "In the Electoral Colony: Kafka in Florida", in: Critical Enquiry 27 (4), 662-702.

Descartes (1986): René Descartes, Meditationes de Prima Philosophia, Stuttgart. Kant (1997): Immanuel Kant, Prolegomena to Any Future Metaphysics, Cambridge.

Kant (1998): Immanuel Kant, Critique of Pure Reason, Cambridge.

Kripke (1982): Saul Kripke, Wittgenstein on Rules and Private Language, Cambridge/MA.

Land (2012): Thomas Land, "Kantian Conceptualism", in: G. Abel/J. Conant (eds.), Rethinking Epistemology, Vol. 1, Berlin/New York, 197-239.

Lewis (1929): Clarence Irving Lewis, Mind and the World Order, New York. McDowell (1994): John McDowell, Mind and World, Cambridge/MA.

McDowell (1998): John McDowell, "Criteria, Defeasibility, and Knowledge", in: J. McDowell, Meaning, Knowledge, \& Reality, Cambridge/MA, 369394.

Price (1932): Henry Habberley Price, Perception, London.

Putnam (1994): Words and Life, Cambridge/MA.

Putnam (1999): Hilary Putnam, The Threefold Cord, New York.

Williams (2001): Michael Williams, Problems of Knowledge, Oxford.

Wittgenstein (1973): Ludwig Wittgenstein, Philosophical Investigations, New Jersey. 